\title{
ELECTROCHEMICAL IMPEDANCE SPECTROSCOPY
}

Shangshang Wang, ${ }^{1}$ Jianbo Zhang, ${ }^{1}$ Oumaïma Gharbi, ${ }^{2}$ Vincent Vivier, ${ }^{2}$ Ming Gao, ${ }^{3}$ and Mark E. Orazem ${ }^{3+}$

${ }^{1}$ School of Vehicle and Mobility, Tsinghua University, Beijing, China

${ }^{2}$ Sorbonne Université, CNRS, Laboratoire Interfaces et Systèmes Electrochimiques (LISE), 4 place Jussieu, F-75005, Paris, France

${ }^{3}$ Department of Chemical Engineering, University of Florida, Gainesville, Florida, 32611 USA,

${ }^{\dagger}$ Corresponding email: morazem@che.ufl.edu 


\section{ABSTRACT}

Electrochemical impedance spectroscopy (EIS) is a powerful tool to investigate properties of materials and electrode reactions. This Primer provides a guide to the use of EIS with a comparison to other electrochemical techniques. The analysis of impedance data for reduction of ferricyanide in a $\mathrm{KCl}$ supporting electrolyte is used to demonstrate the error structure for impedance measurements, the use of measurement and process models, as well as the sensitivity of impedance to the evolution of electrode properties. This Primer provides guidelines for experimental design, discusses the relevance of accuracy contour plots to wiring and instrumentation selection, and emphasizes the importance of the KramersKronig relations to data validation and analysis. Applications of EIS to battery performance, metal and alloy corrosion, and electrochemical biosensors are highlighted. Electrochemical impedance measurements depend on both the mechanism under investigation and extrinsic parameters, such as the electrode geometry. Experimental complications are discussed, including the influence of nonstationary behaviour at low frequencies and the need for reference electrodes. Finally, emerging trends in experimental and interpretation approaches are also described. 


\section{[H1] Introduction}

Electrochemistry is a discipline encompassing all heterogeneous chemical reactions involving electron transfer, homogeneous reactions that influence reactions at electrode surfaces, properties of the interfaces (the double layer) and bulk properties of electrolytes. Electrochemical reactions are at the root of several research areas including energy conversion and storage, corrosion, sensors and biosensing applications, as well as the production of commodity materials such as aluminum and chlorine. The development of several electrochemical techniques such as cyclic voltammetry (CV), chronoamperometry and chronopotentiometry, scanning electrochemical microscopy (SECM), and electrochemical impedance spectroscopy (EIS), was required to enable studying these reactions across this broad range of application settings. Each of these techniques has expanded in recent decades, as a result of advances in instrumentation and modeling. ${ }^{1,2}$

From a mechanistic point of view, an electrochemical reaction at an electrode/electrolyte interface can be decomposed into a series of multi-step processes (mass transport, charge-transfer processes, adsorption), each occurring at distinct rates. The individual steps are time dependent and may occur at different time scales. Therefore, the use of transient techniques such as EIS, which enables the analysis of time-dependent mechanisms based on the response (current or potential) of the electrochemical system collected at selected frequencies, is required to facilitate evaluation of electrochemical systems. The EIS technique is broadly applicable because it can provide an understanding of the electrochemical mechanisms occurring at an electrified interface in a single measurement. These underlying mechanisms include those involved in operating commercial batteries, the corrosion of metals and alloys and electrochemical biosensors.

Textbooks, monographs ${ }^{2-5}$ and review articles have been dedicated to EIS that are specific to the applications. ${ }^{6-12}$ The history of EIS has also been retraced, ${ }^{13,14}$ highlighting the evolution of the technique from the first measurement of electrolyte conductivity using alternating current in the mid-19 ${ }^{\text {th }}$ century ${ }^{15,16}$ to the measurement of interfacial capacitance [G] ${ }^{17}$ or the measurement of diffusivity. ${ }^{18}$ EIS has benefited from the development of instruments, such as the first potentiostats [G] and the rotating disk electrode [G]. Potentiostats enable the control of the working-electrode potential referenced to an electrode at its equilibrium redox potential ${ }^{19}$ and the rotating disk electrode affords the well-defined transport of reactants and products to the electrode surface. ${ }^{20}$ The development of mathematical models, such as those for porous electrodes that describe the impedance response as a function of the pore geometry in the presence or absence of electrochemical reactions, have enabled a better understanding 
of complex electrochemical systems. ${ }^{21,22}$ EIS has also allowed for better comprehension of intermediate adsorption on electrode surfaces, ${ }^{23,24}$ particularly for multi-step mechanisms, including electrochemical reactions coupled by adsorbed reaction intermediates, electrochemical reactions coupled with homogeneous or heterogeneous chemical reactions, and photoelectrochemical reactions ${ }^{25,26}$. Examples include iron dissolution in an acidic solution ${ }^{27,28}$ and corrosion of magnesium. ${ }^{29,30} \mathrm{EIS}$ is a technique of choice for the study of porous electrodes ${ }^{21,22,31}$ because the output is directly affected by the porosity of the electrode, which may allow the pore size to be evaluated. ${ }^{32-34}$ Together, advances in instrumentation and models provide the capability for detecting multi-step mechanisms and define modern EIS. ${ }^{2,35}$

CV is often preferred to EIS for the study of electrochemical steps coupled with chemical reactions, whose kinetics can be measured by varying the potential scan rate. ${ }^{36-39}$ In contrast to $\mathrm{CV}$ where the entire potential domain is scanned at a given scan rate, EIS offers the unique advantage of being able to perform measurements at different potentials. Interestingly, the potential dependence of the charge-transfer coefficient was inferred from EIS measurements on aromatic compounds with fast reaction kinetics, revealing a good agreement with the predicted values using the Marcus theory for outer-sphere electron transfers. ${ }^{40}$ The potential dependence of the charge-transfer coefficient was also observed by CV, but it requires the use of convolution sweep voltammetry ${ }^{41}$ or the comparison of CV data (the shape of the voltammogram, the peak separation, the peak current) to digital simulations. ${ }^{42} \mathrm{CV}$ and EIS are therefore complementary techniques, and the choice of which technique is best to use depends on the process that each user is seeking to characterize.

EIS is a type of transfer-function measurement, commonly used in the analysis of linear timeinvariant systems. ${ }^{2}$ In the case of an electrochemical system, the main difficulty is that the system must remain in a stationary state throughout the measurement. EIS uses a small-amplitude potential or current periodic perturbation to excite the electrochemical system at different frequencies, as illustrated in Figure 1. By measuring the response (current or potential) of the system to this perturbation, a transfer function is calculated that is the electrochemical impedance of the system in the case of an electrochemical cell. The impedance $Z$ can be expressed as ${ }^{2}$

$$
Z(\omega)=\frac{\tilde{V}(\omega)}{\tilde{l}(\omega)}=\left|\frac{\tilde{V}(\omega)}{\tilde{l}(\omega)}\right|(\cos \phi(\omega)+\mathrm{j} \sin \phi(\omega))=Z_{\mathrm{r}}+\mathrm{j} Z_{\mathrm{j}}
$$

where $\omega$ is the angular frequency, related to the frequency $f$ in $\mathrm{Hz}$ by $\omega=2 \pi f, \phi$ is the phase angle between the input and the output signals, and $\mathrm{j}=\sqrt{-1}$ is the imaginary number. The variables $V /$ and $9 / \mathrm{c}$ 
are phasors, which are complex time-invariant numbers that account for the amplitude and phase of a sinusoidal function. The electrochemical impedance, as defined by equation (1), is a frequency-dependent complex number [G], whose real part $Z_{\mathrm{r}}$ is the resistance [G] and the imaginary part $Z_{\mathrm{j}}$ is the reactance [G]. Although the IUPAC conventions ${ }^{43}$ holds that the real part should be represented by $Z^{\prime}$ and the imaginary part denoted by $Z^{\prime \prime}$, the use of primes is too easily confused with the notation for spatial derivatives in the engineering literature. Thus, the notation used in the present work is that the real part is denoted by a subscript " $r$ " and the imaginary part is denoted by a subscript " $\mathrm{j}$ ".

EIS measurements should be designed to conform to the Kramers-Kronig relations (see Box 1), which are derived under the assumptions that the system under investigation is linear, stable, and causal (see Box 2). The perturbation amplitude required to achieve a linear response with an appropriate signal-tonoise ratio is generally determined experimentally for each system under study. Although a typical amplitude for potentiostatic modulation may be on the order of $10 \mathrm{mV}$, amplitudes as large as $1 \mathrm{~V}$ may be used for the impedance response of high-resistivity lubricating fluids. The Kramers-Kronig relations may be applied as a tool to determine which part of the measured frequency range is uncorrupted by instrument or nonstationary artifacts.

This Primer provides a description of the EIS technique and its principle, including the main aspects of the measurement procedure, data representation and analysis, but is not intended to cover the fundamentals of electrochemistry that can be found elsewhere ${ }^{1,44,45}$. The tools that will help design and perform a valid EIS measurement are described here with specific attention drawn to the choice of cell configuration, measurement settings (Experimentation) and data validation (Results). Several examples and applications are presented in order to introduce the different methods of data representation and interpretation. Finally, the challenges of this technique and an outlook of how EIS will likely evolve in the near future are presented and discussed.

\section{[H1] EXPERIMENTATION}

The use of EIS requires a number of steps, from the measurement procedure to data analysis. Despite the technique being incorporated into most modern potentiostat software, the first step is to make a correct measurement, which is the focus of this section. The EIS measurement system includes the samples and the cells, the instruments and the connection of cells with the instruments ${ }^{46}$. 


\section{[H2] TEST SAMPLES AND CELLS}

A cell with two, three or four electrodes can be used depending on the measurement to be carried out as shown in Fig. 2. ${ }^{1,47}$ The two-electrode system (Fig. 2a) is used in cases where it is difficult to insert a reference electrode, such as batteries and fuel cells. The measured response is the sum of all contributions between the working electrode and the counter electrode, which complicates the interpretation of the impedance response. The three-electrode arrangement (Fig. $\mathbf{2 b}$ ) is the classic device used for all analytical electrochemical measurements ${ }^{48,49}$ that employs a working electrode, which is the sample of interest, a counter electrode and a reference electrode. The use of a reference electrode enables studying the working electrode response independent of the processes taking place at the counter-electrode. A four-electrode setup (Fig. 2c) is used for the characterization of electrolyte conductivity, ${ }^{50}$ free-standing films, ${ }^{51}$ embedded rebar in concrete ${ }^{52}$ and the interface between two immiscible electrolyte solutions. ${ }^{53}$ Two reference electrodes are positioned on either side of the interface to measure the potential and the two other electrodes allow for the passage of the current. The investigation of electrolytes or films without the confounding influence of working and counter-electrode impedances can be done using the four-electrode system. The chosen cell configuration depends on the system being evaluated.

The area of the counter electrode is normally much larger than that of the working electrode to minimize its contribution to the cell impedance. This size difference is especially important for twoelectrode measurements in which the measured impedance includes contributions from both the working and counter electrodes. Although a uniform current and potential distribution on the working electrode are desirable, practical considerations often force the use of electrode configurations in which the current and potential distributions are not uniform. Frequency dispersion caused by non-uniform current and potential distributions distort the high-frequency impedance response, which complicates the interpretation of the impedance data. The geometry-induced frequency dispersion can be avoided by using small working electrodes or by eliminating the frequencies larger than the characteristic frequency

$$
f_{\mathrm{c}}=\frac{1}{2 \pi R_{\mathrm{e}} C}
$$

where $R_{\mathrm{e}}$ is the high-frequency ohmic resistance [G] between the working and the reference electrodes and $C$ is the capacitance [G] of the working electrode-electrolyte interface. ${ }^{54}$

The counter electrode is sometimes placed in a separate compartment to prevent its reaction products from interfering with the working electrode. This compartment is ionically connected with the working 
electrode compartment, usually with a glass/ceramic frit or asbestos threads. The reference electrode should provide a stable potential measurement against which to control the potential of the working electrode. There are two approaches for the placement of the reference electrode. Placing the reference electrode close to the working electrode, such as using a Luggin tube in a glass cell ${ }^{55}$ (Fig. 2b), results in a smaller contribution of the ohmic resistance. In contrast, placing the reference electrode far from the working electrode has the advantage that, for some geometries such as a disk electrode, a relationship exists between the electrolyte conductivity, the ohmic resistance and the electrode dimension, ${ }^{56}$

$$
R_{\mathrm{e}}=\frac{\pi}{4} \frac{r_{0}}{\kappa}
$$

where $r_{0}$ is the disk radius and $\mathrm{k}$ is the electrolyte conductivity. The high-frequency ohmic resistance can be estimated using equation (3) because the electrolyte conductivity is often known, thus providing a check on the measurement quality.

High-frequency artifacts may appear when using an ordinary reference electrode for measurements taken using conventional three-electrode arrangements (Fig. 2b). The impedance of the reference electrode may decrease in the high-frequency region ( $\sim 100 \mathrm{kHz})$, increasing the current flowing through it, which would result in a fluctuation of the reference potential and afford abnormal impedance results. However, placing a capacitor (the value of which depends on the electrolyte conductivity) in series with a platinum wire that is connected in parallel to the reference electrode to bypass the high frequency component of current or noise can relieve this abnormality. ${ }^{57}$

\section{[H2] INSTRUMENTATION}

Along the course of developing the EIS measurement technique, instruments with different measurement principles have been proposed, including AC bridges, ${ }^{14,58}$ Lissajous curves, ${ }^{2}$ phase-sensitive detection and lock-in amplifier, ${ }^{59}$ frequency-response analyzers, ${ }^{4,60}$ Laplace transforms, ${ }^{61}$ and wavelet transforms. ${ }^{62}$ The dominant approach used by modern EIS instruments, provided by vendors such as Solartron, Biologic, Gamry, Metrohm and Zahner, falls in the category of frequency-response analyzers (FRA) that employ the orthogonality of sines and cosines to determine the real and imaginary parts of the complex impedance at a specified frequency. The discussion in the present work will accordingly emphasize FRAs.

\section{[H3] ACCURACY CONTOUR PLOTS}

The EIS accuracy depends on the measurement frequency and the impedance of the sample. Each device and associated cables can be characterized by an accuracy contour plot, which depicts the levels 
of accuracy for the magnitude and phase angle of impedance based on the value of frequency and magnitude of impedance. Such accuracy contour plots should be evaluated to see if the test sample of interest falls into the area with adequate accuracy.$^{63} \mathrm{~A}$ generic accuracy contour plot for potentiostatic modulation is shown in Fig. $\mathbf{2 d}$. Line " $A$ " is based on the minimum current resolution and can be moved by changing the potential perturbation amplitude. The absolute high-impedance limits of a potentiostat and associated cables can be obtained by measuring the impedance in which the wires are not connected, simulating an infinite cell impedance. The result yields the effective capacitance of the leads and instrumentation shown as line " $\mathrm{B}$ ". Line " $\mathrm{C}$ " corresponds to the maximum frequency capability of the instrument. The absolute low-impedance limits can be obtained by measuring the impedance in which the wires are shorted, simulating a zero cell-impedance. The result yields the effective inductance (line " $D$ ") and resistance (line " $E$ ") of the leads and instrumentation. A zone is indicated in which impedance measurements may be made with error less than $1 \%$ in magnitude and $2^{\circ}$ in phase. A second zone corresponds to errors larger than $10 \%$ and $10^{\circ}$ for magnitude and phase, respectively. Measurements outside the boundary formed by lines $A$ through $E$ are not possible.

The measured impedance can be represented by the electrical circuit (Fig. 2e), and the relationship between measured impedance, $Z_{\text {meas }}$, and cell impedance, $Z_{\text {cell }}$, is given by

$$
Z_{\text {meas }}=\frac{\left(R_{\text {wire }}+Z_{\mathrm{L}, \text { wire }}+Z_{\text {cell }}\right) \times Z_{\mathrm{C} \text {,wire }}}{R_{\text {wire }}+Z_{\mathrm{L}, \text { wire }}+Z_{\text {cell }}+Z_{\mathrm{C} \text { wire }}}
$$

where $Z_{\mathrm{C} \text {,wire }}, Z_{\mathrm{L} \text {,wire }}$ and $R_{\text {wire }}$ are the impedances associated with the capacitance, inductance, and the resistance of the wires, respectively. Instrument vendors usually use short shielded wires to reduce the contribution of the wire capacitance and inductance and often provide accuracy contour plots with wires coming with the instrument. However, the positions of the limits in accuracy contour plots are strongly affected by the wires used to connect the instrument to the cell. To this end, users should always generate a new accuracy and check it if they need to use longer wires for special purposes, such as connecting the cell far away from the instrument.

The wires connecting the equipment and cells in EIS measurements form two loops, one includes the two wires bearing the current and the other bears the two wires sensing the voltage (Fig. 2f). The contribution of wire properties can be neglected and measured impedance is the same as the cell impedance for most measurements. However, for systems exhibiting small impedance, the use of long wires may give rise to high-frequency artifacts because the magnetic field generated by the alternatingcurrent-carrying leads will drive an alternating potential in the sense leads (Fig. $\mathbf{2 h}$ ). This phenomenon is called mutual inductance, which can be reduced by minimizing the loop area between the two current 
wires and the two voltage wires via a tight-braided twist (Fig. 2g).$^{64}$ Another solution includes maximizing the distance between the current-carrying and the voltage-sensing wires. ${ }^{63}$ Finally, orientating the clamp (bayonet) of the current and voltage wires in a cross configuration, that is perpendicular to each other, may help to further reduce this interaction.

\section{[H3] SeTTINGS}

The quality of the impedance measurement is controlled by a series of parameters, including selection of potentiostatic or galvanostatic modulation, perturbation amplitude, frequency range and the number of cycles used to perform the measurement at each frequency. In principle, EIS can be obtained either by applying a current perturbation and measuring the potential response, in the galvanostatic mode, or by applying a potential perturbation and measuring the current response, in potentiostatic mode. The choice of potential or current regulation depends on the electrochemical systems, and a first criterion for this selection is the shape of the steady-state current potential curves, which should be generated before the EIS measurement as a best practice. When the slope of the current-potential curve is very sharp (for example, the dissolution of zinc), the galvanostatic mode is usually preferred because the potentiostatic mode may lead to overloading of the cell and the current measurement circuits of the potentiostat. For steep slopes of the current-potential curve, a small change in potential might lead to a large change in current. In general, galvanostatic impedance is more suitable for noninvasive probing of metal corrosion at the open-circuit potential and for measuring most high-energy electrochemical devices, where impedance is low and current levels are high. However, for electrochemical systems with larger impedance, the potentiostatic mode is generally employed.

The amplitude of the perturbing current or potential must be determined experimentally. The perturbation amplitude should be small enough to make the system linear, but as large as possible to get the best signal-to-noise ratio. Selection of the amplitude depends both on the polarization curve of the system and the noise level of the measurement system. The optimal perturbation amplitude is not necessarily the same over the entire frequency range and it may be compulsory to adapt it to make a good measurement because electrochemical systems involve different processes. For potentiostatic EIS mode, an AC potential signal with peak-to-peak amplitude of 5 to $15 \mathrm{mV}$ is commonly used. However, for a system with large impedance or significant noise, the amplitude may be increased so long as linearity is assured. The potential changes associated with galvanostatic modulation depend on the frequencydependent impedance of the system. As the impedance of the systems may change by orders of magnitude with frequency, the potential swing at low frequencies from a fixed galvanostatic modulation 
may cause nonlinear behaviour. In this case, the amplitude of the current perturbation should be adjusted as a function of frequency. Algorithms for frequency-dependent galvanostatic modulation have been developed. ${ }^{65,66}$ Distortions of the expected ellipse in low-frequency Lissajous plots (current as a function of potential) provide a good indicator for nonlinear response. ${ }^{67,68}$ If distortions from a perfect ellipse are observed, the perturbation amplitude should be reduced. The monitoring of the spectral contents at higher harmonics of the response signal may also be used to determine the suitable range of perturbation amplitude. These experimental approaches are suitable for both potentiostatic and galvanostatic modulation.

The power of EIS lies in its ability to probe processes in systems across a wide frequency range. Ideally, the frequency range should be set to match the dynamic range of the system under study. Modern EIS instruments can easily cover a broader range from $\mathrm{MHz}$ to $\mu \mathrm{Hz}$, spanning 12 orders of magnitudes. In practice, the accuracy of the equipment may drop significantly at high frequencies, as shown in Fig. $\mathbf{2 d}$, and the measurement duration may become prohibitively long or the system may no longer be stationary in the low-frequency limit (see Box 1). As a result, the typical frequency range for electrochemical measurements, including energy conversion as well as storage device and corrosion, is $10 \mathrm{kHz}$ to $10 \mathrm{mHz}$. Usually, 7 to 10 points per frequency decade (for example, from $100 \mathrm{~Hz}$ to $10 \mathrm{~Hz}$ ), equally spaced logarithmically, are required for measuring an impedance spectrum with sufficient accuracy for a detailed data analysis. It is preferable to start the measurement from the high-frequency limit sweeping towards the low-frequency limit, because the operator has the opportunity to grasp the main behaviour of the system in a short period of time. If anything goes wrong, such as current overloads or excessively noisy signals, the operator can abort the measurement and make any necessary change or adjustment to the settings or the cell.

The stochastic error structure or noise level of the measurement is influenced by the number of cycles used to measure the impedance at each frequency. The precision of the measurement increases with the square-root of the integration cycles. This effect from the number of cycles used is particularly worthwhile at high frequencies because noise content is high and time overhead for repetition is low. At very low frequencies, this effect is less significant due to the increased time overhead on the one hand, and the change of the nature of the predominant noise from external electromagnetic interference to the system non-stationarity. For some instruments, an auto-integration mode is used to select the number of cycles, which is usually three or larger. In contrast, the user is allowed to choose between fast, normal 
and low-noise options that influence the number of cycles used for the measurement for other instruments.

Introducing a delay of one or two cycles before the impedance measurement will help to reduce the errors because a transient response may occur in the cell during the change from one frequency to another. Similarly, there is usually a startup transient before the entire sequence of the measurement, which tends to corrupt the first frequency measured. A simple way of obviating this problem is to ignore the first frequency in subsequent regression analyses. In addition, the measured results within $\pm 3 \mathrm{~Hz}$ of the line frequency and its first harmonic (for example, $50 \mathrm{~Hz}$ and $100 \mathrm{~Hz}$ in Europe or $60 \mathrm{~Hz}$ and $120 \mathrm{~Hz}$ in North America) are prone to stochastic noise. ${ }^{2}$ Data at these frequencies should be discarded in regression analyses, or, preferably, not measured. The user can check the EIS plot to spot any dispersed point(s) near the line frequencies. If there is, just remove these data before regression.

\section{[H2] ENVIRONMENT CONTROL}

Many electrochemical parameters have a sensitive dependence on temperature. To ensure reliable and repeatable measurements, a tight control of the cell temperature is required. Temperature control may be achieved using a thermal bath for glass cells, a heater-and-fan feedback control for a fuel cells, and an environmental chamber for batteries. This precaution is especially necessary for measurements at low frequencies. For low-current measurement, cells must be placed into a Faraday cage to shield the electrical noise from the environment. The Faraday cage should be connected to the ground to eliminate the voltage difference between the interior of the cage and the ground reference. Otherwise, this voltagedifference tends to couple capacitively to the electrodes, leading to only partial shielding of the external electro-magnetic interference. ${ }^{69}$ Mechanical vibration may become an issue for systems with extremely small current and high sensitivity to electrical contact, such as when probing the EIS of a single particle. In these situations and those similar, an anti-vibration table should be used. ${ }^{70}$

\section{[H2] DEBUGGING AND CORRECTION}

When a doubt arises about the quality of a measurement, debugging tests could be performed on an electrical circuit that comes with the potentiostat or an electrical circuit with the similar electrical characteristics as the electrochemical system under study. The use of the appropriate electrical circuit with known impedance response allows for identifying instrument and wiring artifacts. An oscilloscope, preferably analog, is extremely helpful in identifying the presence, magnitude, frequency range and the nature of the electro-magnetic noise. In addition, the nonlinearity can be captured if a significant component is detected at high multiples of the perturbation frequency. Some EIS instruments have a 
digital oscilloscope in the menu that should be exploited in the initial phase to determine the appropriate range of the amplitude of the perturbing signal. Distortions of the expected ellipse in low-frequency Lissajous plots provide a good indicator for nonlinear response. ${ }^{67,68} \mathrm{Impedance}$ data can also be evaluated by regression of a measurement model to determine the stochastic error structure and the frequency range that is consistent with the Kramers-Kronig relations. ${ }^{71-73}$

\section{[H1] RESULTS}

The first step towards data analysis is use of graphical methods to visualize and interpret the impedance data. To emphasize a specific feature or behaviour, impedance data need to be presented in different formats that include: the Nyquist representation for mass transfer and kinetic behaviour; the Bode representation for frequency-dependent behaviour; the admittance format for capacitive behaviour at high frequency; and the complex-capacitance format for capacitive behaviour of a dielectric system. The parameters associated with resistance and capacitance can be extrapolated by graphical methods. Regression and statistical analysis provide more advanced quantitative analysis of impedance data. The analysis includes checking for consistency with the Kramers-Kronig relations, finding the error structure of impedance measurements, and extrapolating parameters by regression of process model. The methods and application to sample data are illustrated in this section.

\section{[H2] GRAPHICAL REPRESENTATION}

Interpretation relies partly on data representation, which is a critical aspect in EIS analysis. The commonly used representations are shown and discussed here.

\section{[H3] Potential-current vs. time and Lissajous curves}

The relation of the sinusoidal potential and current as the function of time at a frequency of $20 \mathrm{~Hz}$ is shown in Figure 3a. The amplitude and phase shift contain important information of impedance data. The phase shift between the input and output signals can be seen more clearly in the Lissajous curve given as Figure $3 b$, obtained by plotting the output signal as a function of the input signal at a specific frequency. In the early years of EIS, Lissajous plots were used to perform EIS measurement at low and high frequencies, respectively. Moreover, the Lissajous plot (Figure $3 b$ ) has several advantages when monitored during the course of the experiment. If distortions of the Lissajous figure are seen, the perturbation amplitude applied to the system should be reduced, at least on the frequency domain where the degeneration of the ellipse is observed. If the Lissajous plot can be made to have an elliptical shape by adjusting the perturbation amplitude, the measurement can be said to be linear. In addition, a shift of 
the electrical signal along the $x$ - or $y$-axis, usually occurring at the low-frequency range, implies a shift of the system to a non-stationary state, resulting in an erroneous measurement in this frequency domain. For example, this can be the case for a battery, if the amount of charge changes during the measurement, or for a corroding system evolving naturally, even slowly, over time. Accordingly, even if the current measuring devices are becoming more and more efficient, their mode of operation is not generally known to the user. The recorded current signal, for example, can be an average over a few cycles or a period of time. Therefore, connecting an oscilloscope [G] to trace the live Lissajous curve is a way to guarantee the validity of the measurements. If the traces of the live Lissajous curves overlap, the measurement at that frequency is not experiencing non-stationary behaviour, which means the system does not change with time.

\section{[H3] BODE AND NYQUIST REPRESENTATIONS}

The Bode (Fig. 3c) and Nyquist (Fig. 3d) representations are obtained over a wide frequency range (typically between $100 \mathrm{kHz}$ and $10 \mathrm{mHz}$ ) and are therefore 3D representations of the experimental results, namely frequency $(f)$, modulus $(|Z|)$ and phase $(f)$ for the Bode diagram or frequency, real part $\left(Z_{\mathrm{r}}\right)$ and imaginary part $\left(Z_{\mathrm{j}}\right)$ for the Nyquist diagram. The Bode and Nyquist representations are the most commonly used in the literature, and they generally allow a preliminary analysis of the system, leading to the identification of elementary processes involved in the mechanism. A typical Bode plot, where the phase angle $(\phi)$ and modulus (|z|) are plotted as a function of frequency, is shown in Fig. 3c. The phase angle and modulus are calculated from the real and imaginary parts from the measurements. The Bode plot is an intuitive illustration of the impedance change with frequency. The phase angle usually tends toward $0^{\circ}$ at high frequency due to the ohmic resistance of the electrolyte, shown in blue dots in Figure 3(c). The Ohmic-resistance-adjusted phase angle has an asymptotic value of $-90^{\circ}$ at high frequency for the ideally polarizable electrode. If there is a CPE behaviour, the asymptotic value at high frequency would be lower than $90^{\circ}$. Thus, plots of the ohmic-resistance-adjusted phase angle provide a direct representation format for a constant-phase element (CPE) behaviour or frequency dispersion behaviour (see Box 3). A typical Nyquist plot, in which the imaginary part is plotted against the real part of impedance data, is shown in Fig. 3d. The Nyquist representation emphasizes larger values of impedance that show the influence of mass transfer and reaction kinetics. Each symbol is the data point measured at a specific frequency and the solid dots are used to designate some typical frequencies. In the case for this sample data, $1.6 \mathrm{kHz}$ is the characteristic frequency for the charge-transfer process of the electrochemical reaction, which can be used to obtain the characteristic time constant. The low-frequency straight line is 
the Warburg impedance for mass-transfer process. The time constant is determined by

$$
\tau=\frac{1}{2 \pi f_{\mathrm{c}}}
$$

where the time constant is $\tau=R C_{\mathrm{dl}}$ and $f_{\mathrm{c}}$ is the characteristic relaxation frequency. Several processes exhibit similar relaxation frequencies, which results in overlapping time constants. However, it is still possible to distinguish these different time constants using strategies such as regression analysis, the use of different graphical representations ${ }^{2,74}$ or a method based on the distribution function of relaxation times. $^{75-77}$

\section{[H3] Other Representations}

Other methods for representing impedance, such as the complex-admittance format and complex-capacity format are less used as compared with the representation methods discussed above. The choice of representation depends on the specific needs for data visualization and interpretation. The admittance is also a transfer function with real and imaginary parts, which is inversely related to the impedance. The admittance format emphasizes the capacitive behaviour at high frequencies. It is commonly used in solid-state systems. The complex-capacitance is defined as

$$
C(\omega)=C_{\mathrm{r}}+\mathrm{j} C_{\mathrm{j}}=\frac{1}{\mathrm{j} \omega\left(\mathrm{Z}-R_{e}\right)}
$$

for an impedance corrected by the ohmic resistance. Like the Nyquist plot, the complex-capacitance format obscures the frequency dependence of the data. The high-frequency asymptotic value can be used to determine the capacitance. Therefore, the complex-capacitance format is usually employed to represent systems for which the capacity is of interest.

\section{[H3] EIS AND ELECTRICAL CIRCUITS}

Electrochemical impedance spectra can be represented as a combination of electrical (resistance, capacitance or inductance) and electrochemical (faradaic) impedances. In particular, thin films on an electrode surface behave like dielectrics, as does the double layer that forms spontaneously on an electrified interface. Therefore, electrical circuits are often used to analyze experimental results, but such an approach masks the physical and chemical properties of the interface. ${ }^{2,4,13}$ All Kramers-Kronigconsistent impedance spectra may be fit by an equivalent circuit, which is the point of using a measurement model (discussed further in REPRODUCIBILITY AND DATA DEPOSITION). The issue is that such models are not unique, and fitting by use of an electrical circuit does not necessarily provide useful 
information concerning the system under investigation. For example, batteries, are most often analyzed in terms of equivalent electrical circuits because of the complexity of the system, ${ }^{78}$ however, mechanistic models make it possible to take into account all the physical chemistry in an increasingly precise manner. ${ }^{79-82}$

Users often prefer one technique over others, but it is important to note that EIS and other widely used electrochemical techniques are complementary. For illustration, a system involving reduced species dissolved in solution (Fig. 3e) is presented using CV (Fig. 3f), chronoamperometry (Fig. 3g), and EIS (Fig. 3h).

The sweep-rate-dependent increase and decrease in value of current with increasing potential in the CV curves (Fig. 3f) reveals the presence of a diffusion-limited system. The difference between the peak potentials at a given scan rate allows the determination of electron-transfer kinetics. The variations in peak intensities as a function of the square root of the potential scan rate allows calculation of the diffusion coefficient.

When the same electrochemical system is studied by applying a potential step, little information is readily apparent from the resulting current as a function of time, shown in Fig. $\mathbf{3 g}$. Inflections in the current response can be seen when time is plotted on a logarithmic scale, shown in the inset for Fig $\mathbf{3 g}$, and these inflections highlight the presence of two time constants The current response is dominated by the cell time constant for the shorter times, that is the electrolyte resistance, $R_{e}$, in series with the double layer capacitance, $C_{d l}$. In contrast, the diffusion of electroactive species is responsible for the current decay for longer times owing to their consumption at the electrode surface. The inset in Fig. $\mathbf{3 g}$ shows the current response to the $R_{e} C_{d l}$ time constant, characteristic of the double-layer charging. This value defines the lower limit time scale ( 2 to 3 times $R_{e} C_{d l}$ ) at which kinetic information can be retrieved, and can be tuned by using an electrode of appropriate size. The use of microelectrodes reduces the ohmic resistance and so the $R_{e} C_{d l}$ time constant (as shown by equation (3)), making it possible to study systems with fast charge transfer, down to the $100 \mu$ s domain. ${ }^{83}$

Similarly, the detailed analysis of the EIS diagram (Fig. $\mathbf{3 h}$ ) allows these same parameters to be determined. The width of the high-frequency capacitive loop yields the charge-transfer resistance associated with the kinetics of the electrochemical reaction, and the frequency at the peak of the highfrequency loop yields the double-layer capacitance (see equation (5)). The tail forming a $45^{\circ}$ slope in the low-frequency range is attributed to the diffusion of electroactive species (Warburg semi-infinite diffusion impedance [G]). Interestingly, the current response to a small-amplitude potential step results in a curve 
(Fig. 3g) that contains the same information as the EIS response, which is enabled by transforming data from time domain to frequency domain using the Fourier transform. ${ }^{84,85}$

\section{[H2] REGRESSION}

Complex nonlinear least-squares regression is used to fit mathematical models to impedance data. The complex nonlinear least-squares approach has the advantage that a common set of parameters are obtained by simultaneous regression of the model to both real and imaginary data. ${ }^{86}$ Commercial programs such as $\mathrm{ZPlot}^{87}$ or ZSimpWin ${ }^{88}$ are available to fit electrical circuit models to impedance data. Noncommercial programs are also available, such as a recent Python-based program for regression that allows both a measurement-model analysis of the data and the ability to regress arbitrary functions. ${ }^{73}$

The quality of the fit may be determined by using a graphical comparison of the model result and the impedance data or, if the experimental error structure is known, by the weighted-chi-squared statistic. Both simplex regression [G] and Levenberg-Marquardt regression [G] strategies are used. ${ }^{89,90}$ Despite being very sensitive to selection of initial guesses, the Levenberg-Marquardt regression method provides confidence intervals for regressed parameters, thus alerting the user to situations where regressed parameters do not have statistical significance. The simplex routine is less sensitive to initial guesses and as a result is easily used, but the absence of confidence intervals represents a severe shortcoming. A hybrid approach is preferred in which simplex is used to provide good initial guesses for the LevenbergMarquardt regression.

\section{[H2] APPLICATION TO SAMPLE DATA}

To demonstrate a systematic procedure for interpretation of impedance data, the data analysis methods discussed above are applied to sample impedance measurements in the following section. The error analysis associated with these sample data is presented in REPRODUCIBILITY AND DATA DEPOSITION.

\section{[H3] SAMPLE DATA}

The sample data were collected for the impedance response of a $5 \mathrm{~mm}$ diameter Pt disk electrode rotating at $120 \mathrm{rpm}$ in an electrolyte containing $0.01 \mathrm{M} \mathrm{K}_{3} \mathrm{Fe}(\mathrm{CN})_{6}, 0.01 \mathrm{M} \mathrm{K}_{4} \mathrm{Fe}(\mathrm{CN})_{6}$, and $1 \mathrm{M} \mathrm{KCl}$ as supporting electrolyte. Overall, this system is widely used as a reference for electrochemical measurements and further experimental details are available elsewhere. ${ }^{91}$ The first frequency measurement was collected after $14 \mathrm{~s}$, and the subsequent measurements were collected after nine hours of immersion. Each measurement required about 19.5 minutes for its acquisition. As shown in Fig. 4a, a substantial difference is seen between the first measurement made and the measurements made after 
$8.9 \mathrm{~h}$. A film is hypothesized to form on the platinum disk, and this film is seen to influence the impedance results. ${ }^{91}$ The regression program used to analyze the data in the present work is available for free noncommercial use. ${ }^{73}$ The installation file includes all the sample data discussed in this subsection, sample process models including the one used to analyze the data, and the Python code used to calculate the convective diffusion impedance response of a rotating disk electrode.

\section{[H3] PROCESS MODEL}

The depressed high-frequency semicircular loop seen in Fig. 4 a can be attributed to the faradaic reaction and the shape of the larger low-frequency loop, with a $45^{\circ}$ line at higher frequencies, can be associated with mass transfer. For the ferri/ferro cyanide system, mass transfer is expected to influence the faradaic reactions. The depressed character of the high-frequency loop is attributed to frequency dispersion that is approximated by a CPE (see Box 3). The origin of the observed CPE is uncertain and the usual explanations in terms of distributions along the surface of the electrode ${ }^{92}$ or through a film ${ }^{93}$ are not likely to apply. However, the coupling between faradaic and charging current may be a possible reason, ${ }^{94}$ but more work is needed to explore this hypothesis.

The circuit representation of the process model is shown in Fig. $\mathbf{4 b}$, and the corresponding mathematical expression is given as

$$
Z=R_{\mathrm{e}}+\frac{R_{\mathrm{t}}+Z_{\mathrm{d}}}{1+(\mathrm{j} \omega)^{\alpha} Q\left(R_{\mathrm{t}}+Z_{\mathrm{d}}\right)}
$$

where $R_{\mathrm{e}}$ is the ohmic resistance, $R_{\mathrm{t}}$ is the charge-transfer resistance, $Z_{\mathrm{d}}$ is the diffusion impedance, and $\alpha$ and $Q$ are parameters for a CPE, that is $Z_{\mathrm{CPE}}=\left((\mathrm{j} \omega)^{\alpha} Q\right)^{-1}$. The diffusion impedance is expressed in terms of a diffusion resistance $R_{\mathrm{d}}$ and a dimensionless diffusion impedance as

$$
Z_{\mathrm{d}}=R_{\mathrm{d}}\left(\frac{-1}{\theta^{\prime}(0)}\right)
$$

The dimensionless diffusion impedance is given by

$$
\frac{-1}{\theta_{\mathrm{i}}^{\prime}(0)}=Z_{(0)}+\frac{Z_{(1)}}{\mathrm{Sc}_{\mathrm{i}}^{1 / 3}}+\frac{Z_{(2)}}{\mathrm{Sc}_{\mathrm{i}}^{2 / 3}}+\ldots
$$

where $Z_{(0)}, Z_{(1)}$, and $Z_{(2)}$ are the three complex solutions to the convective diffusion impedance corresponding to three terms in the series expansion for the axial velocity near the disk electrode, and 
the Schmidt number is expressed as $\mathrm{Sc}=v / D_{\mathrm{i}}$, where $v=\mu / \rho$ is the kinematic viscosity and $D_{\mathrm{i}}$ is the diffusion coefficient for the reacting species. ${ }^{2}$ The dimensionless diffusion impedance for a stationary film in terms of a diffusion time constant $\tau=\delta_{\mathrm{N}, \mathrm{i}} / D_{\mathrm{i}}$, where $\delta_{\mathrm{N}, \mathrm{i}}$ is the Nernst stagnant diffusion layer thickness,

$$
\frac{-1}{\theta_{\mathrm{i}}^{\prime}(0)}=\frac{\tanh \sqrt{\mathrm{j} \omega \tau}}{\sqrt{\mathrm{j} \omega \tau}}
$$

is often used to account for the impedance of a rotating disk. The advantage of equation (9) over equation (10) is that it provides a more accurate model for the diffusion impedance response of a rotating disk electrode with no additional parameters.

\section{[H3] REGRESSION}

The regression was weighted by the error structure deduced from the three measurements collected after 8.9 hours of immersion, such that

$$
\sigma_{\mathrm{r}}=\sigma_{\mathrm{j}}=\beta\left|Z_{\mathrm{r}}\right|+\gamma|Z|^{2}
$$

where $\beta=0.000291$ and $\gamma=3.76 \times 10^{-5} \Omega^{-1} \mathrm{~cm}^{-2}$. Five low-frequency data points were found to be inconsistent with the Kramers-Kronig relations and were removed from the first data set (measured at 14s). No low-frequency data were removed from the data collected after 8.9 hours. Data with frequencies above $4.3 \mathrm{kHz}$ were removed to eliminate the contribution of ohmic impedance associated with nonuniform current and potential distributions. The resulting regression results are illustrated as lines in Fig. 4a and the values of the fitted parameters are summarized in Table 1, which were all statistically significant. The Schmidt number for the measurement at $14 \mathrm{~s}$ is $1076 \pm 14$, on the order of the value expected for a bare electrode under the measurement conditions. There was an observed increase in the Schmidt number after $8.9 \mathrm{~h}$ of immersion. Similarly, the charge-transfer resistance and the diffusion resistance increased with elapsed time. The effective capacitance was evaluated based on the values from regression results, following the Brug formula, ${ }^{92}$

$$
C_{\text {eff }}=Q^{1 / \alpha}\left(\frac{R_{\mathrm{e}} R_{\mathrm{t}}}{R_{\mathrm{e}}+R_{\mathrm{t}}}\right)^{(1-\alpha) / \alpha}
$$

where $R_{\mathrm{e}}$ is the ohmic resistance. $R_{\mathrm{t}}$ is the charge-transfer resistance, and $\alpha$ and $Q$ are the values associated with the CPE. Equation (12) relates the CPE parameters to capacitance for a surface distribution 
of time constants. The values shown in Table 1 are in the range expected for a double-layer capacitance. The characteristic frequencies, calculated using equation (2), are larger than the maximum frequency used in the regression, confirming that the influence of ohmic impedance was avoided.

The analysis presented here demonstrates the discriminating power of impedance spectroscopy. The method allows an in-situ interogration of an electrochemical system. The method is noninvasive such that the potential excursion is very small as compared to $\mathrm{CV}$, and it can be used to evaluate the ohmic resistance, the electrode capacitance, the charge-transfer resistance, which is inversely related to the reaction rate constant, and the Schmidt number. The EIS measurement is very sensitive to the evolution of electrode properties, in this case, showing the influence of the growth of a film on the electrode. The presence of a film increases the charge-transfer resistance, increases the electrode capacitance, and influences mass transfer. The systematic changes revealed by the impedance response are not visible in the steady-state current at the applied potential given in Table 1.

\section{[H1] APPLICATIONS}

EIS is widely applied across diverse electrochemical cells, devices and systems, including energy storage and conversion, corrosion, sensors and biomedical systems. This method can be used to provide simple system diagnostics in-situ and in-operando, to identify the presence and evaluate the relative importance of different processes or to extract detailed physical and chemical information about a process of interest.

\section{[H2] PROCESS DECOUPLING AND DIAGNOSING}

In the initial stage or pre-test, EIS may be used to probe the general behaviour of the system, similar to the use of the $\mathrm{CV}$ technique in the time domain. $\ln \mathrm{CV}$, voltage is swept across a wide range (1 2 V) to expose current peaks corresponding to different electrochemical reactions, in the anodic and cathodic scans. In EIS, frequency is swept across several orders of magnitude to expose impedance features and signatures at different time scales. Major features can be easily identified, while abnormal behaviours can be easily spotted.

EIS provides a powerful means for decoupling processes occurring at different time scales as compared to time-domain methods. The typical EIS spectra and the corresponding physical processes of iron corrosion in sulfuric acid solution ${ }^{95}$, solid oxide fuel cells ${ }^{96}$, lithium-ion batteries ${ }^{80}$ and polymer electrolyte fuel cells ${ }^{97}$ are shown in Figure 5. Generally, electrolyte resistance dominates at the highfrequency range, diffusive impedance dominates at the low-frequency ranges, and interfacial processes 
dominate at the intermediate-frequency range. Inductive loops are frequently observed, as shown here for a corrosion process and for a polymer-electrolyte fuel cell. The inductive loops for the corrosion of iron in sulfuric acid were attributed to the coupling of electrochemical reactions by three intermediate species. ${ }^{28,98}$ Depending on the operating conditions, the inductive loops for the polymer-electrolyte fuel cell have been attributed to water transport ${ }^{99}$, reactions coupled by oxidation of the Pt catalyst ${ }^{100}$ or adsorbed intermediates (discussed further in LIMITATIONS AND OPTIMIZATIONS).

These physical processes can be further decoupled. For example, a physics-based model for lithiumion batteries was able to resolve the controversial attribution of EIS features at low frequency to diffusion in either electrolyte or active particles. ${ }^{79,80,101}$ The contributions from different parts in the cell (the anode, the cathode, the electrolyte) may be differentiated even without the use of a reference electrode. ${ }^{102,103}$ The diagnostic results from EIS can help identify the rate-determining process, and are hence valuable for the design and evaluation of electrochemical devices.

\section{[H2] MECHANISM IDENTIFICATION AND REACTION PARAMETER ESTIMATION}

EIS can be employed to identify reaction or failure mechanisms from EIS signatures or the evolution of EIS features. Once the mechanism is identified, EIS can be employed to estimate the reaction parameters, such as charge-transfer resistance and the diffusion coefficient. A systematic way to identify the reaction mechanism composed of different elementary steps has been established, showing that the development of impedance models from assumed reaction kinetics is superior to the interpretation of impedance data in terms of an intuitively assumed electrical circuit. ${ }^{104}$ One way to validate the proposed mechanism is to check whether a single set of parameters can describe the current-voltage curve and the electrochemical impedance measured at different potentials. ${ }^{28,98,105-107}$

The underlying mechanism for the deposition of hydrogen under potential was explored using EIS. ${ }^{108}$ Dynamic EIS and dynamic CV were used to resolve the controversy over the failure mechanism during subzero startup of a proton-exchange membrane fuel cell. ${ }^{109}$ The exchange current density, related to the charge transfer resistance, can be estimated from EIS at the open circuit voltage. ${ }^{110}$ The reaction order of different species can be estimated from the exchange current density at different reactant concentrations (activities). ${ }^{111}$ Finally, the activation energy $\left(E_{\mathrm{a}}\right)$ can be estimated from the exchange current density at several reaction temperatures ${ }^{110,112}$, as shown in Error! Reference source not found.6. 
[H2] MONITORING

The features in EIS can be attributed to specific components or processes by examining the trend of the impedance data while systematically varying the parameters. The adjusted parameter can be external, such as operation conditions, or internal, such as the cell design parameters. After the EIS features of a system are thoroughly understood, impedance results at several or even a single frequency can be used to monitor the status of the system and subsequently to control the operation condition.

In a proton-exchange membrane fuel cell, impedance at a single frequency (around $1 \mathrm{kHz}$ ) is used to monitor the water content of the membrane, based on which the operation conditions are adjusted to prevent both flooding and drying out. ${ }^{113}$ In lithium ion batteries, EIS is used to estimate the internal temperature of the cell, ${ }^{114}$ which constitutes a more reliable and earlier indicator for possible thermal runaway than the surface temperature. For the online monitoring of EIS, a simplified equivalent electric circuit model, using the general-purpose CPE, usually proves to be adequate. EIS is also widely used for biosensing applications, since it allows the real-time monitoring of tiny changes at the electrode/electrolyte interface. ${ }^{115-117}$ For example, EIS methods enabled the detection of breast cancer cell concentration via covalent grafting of the specific antibody directed against the receptor anti c-erbB2 on electrogenerated polymers (Fig. 7). ${ }^{117}$ The resistance determined from the zero-frequency limit of the impedance is correlated to the concentration of cancer cells, as shown in Fig.7. The impedimetric biosensor can measure the EIS continuously and can monitor the concentration of cancer cells with high sensitivity and efficiency.

\section{[H2] MATERIAL, STRUCTURE, PROCESS CHARACTERIZATION}

Once the frequency response of the system being evaluated is well-understood, EIS can be used to characterize the materials, structures and processes of interest, and extract the associated structural, kinetic and mass transfer parameters. To improve the accuracy, it is advisable to devise simplified systems for such purposes.

For material characterization, it is common practice in the laboratory to use EIS with a four-electrode setup to measure the electrolyte conductivity, be it liquid or solid. The four-electrode configuration was used to explore the solvation/desolvation behaviour of the lithium ion, identifying the desolvation of $\mathrm{Li}^{+}$ ion as the major contributor to the interfacial resistance in lithium-ion batteries. ${ }^{118}$ For structure characterization, an electrochemical porosimeter enabled estimating the pore size distribution in a porous electrode using EIS. ${ }^{119,120}$ Different pore size distributions correspond to different CPE behaviour, as shown in Figure 8. Also, for process characterization, EIS has been used to estimate the charge and mass transfer 
properties of a lithium-ion battery component. ${ }^{121}$ To improve the power of process differentiation, a generalized transmission-line model for porous electrodes ${ }^{80}$ was developed.

\section{[H1] REPRODUCIBILITY AND DATA DEPOSITION}

As EIS measurements are very sensitive to sample preparation and the conditions to which the electrode has been exposed, the use of data repositories as a means to enhance reproducibility has not been widely adapted. Although round-robin tests have been attempted, ${ }^{122}$ these have shown scattered results, partly because the protocols used emphasized speed of measurement over data quality. To this end, impedance measurement and interpretation are considered to be specific to each individual application.

Two types of error structure may be considered for impedance measurements. Sample-to-sample variability is important for use of impedance data for quality control, such as evaluating the durability of coatings. ${ }^{123} \mathrm{~A}$ minimum of eight samples has been suggested for the commercial evaluation of the relative performance of different coatings, and 12-18 samples for assessing properties of an individual coating. The impedance of these coatings would be evaluated as a function of time under accelerated degradation protocols to assess film durability. ${ }^{124}$

The second type of error structure is that associated with each individual measurement. The error structure of impedance data may be considered in terms of the residual errors for the regression of a model to impedance data. The residual errors are expressed as ${ }^{2}$

$$
Z-\hat{Z}=\varepsilon_{\text {fit }}+\varepsilon_{\text {stoch }}+\varepsilon_{\text {bias }}
$$

where $\varepsilon_{\mathrm{fit}}$ is the contribution to the residual error that can be attributed to the use of an inadequate model, $\varepsilon_{\text {stoch }}$ is the contribution due to stochastic errors, and $\varepsilon_{\text {bias }}$ is the contribution due to bias errors. The stochastic errors have a mean value equal to zero and can be characterized by a standard deviation. The bias errors may be considered to be those errors that cause the impedance data to be inconsistent with the Kramers-Kronig relations. Error structure and sample variability should always be evaluated for a scientific analysis of impedance data, although it is not yet commonplace.

The step-by-step procedure for assessing the error structure of replicated impedance spectra involves fitting the Voigt measurement model shown in Fig. 9a to each impedance measurement using modulus weighting. ${ }^{71}$ The impedance is given by 


$$
Z=R_{0}+\sum_{\mathrm{k}}^{\mathrm{K}} \frac{R_{\mathrm{k}}}{1+\mathrm{j} \omega \tau_{\mathrm{k}}}
$$

where $R_{0}$ is the leading resistance, similar to the ohmic resistance used in equation (7), $\tau_{\mathrm{k}}=R_{\mathrm{k}} C_{\mathrm{k}}, k=1 \ldots$ $K$, and $K$ is the number of Voigt elements. The estimate of the standard deviation of the stochastic part of the error structure is obtained from the standard deviation of the residual errors for the regression. It is important that the fit to each spectrum includes the same number of Voigt elements. The resulting standard deviation for the data presented in Fig. $\mathbf{4 a}$ is presented as $100 \sigma|\mathrm{Z}|^{-1}$ in Fig. 9b, where the standard deviation for the real part of the impedance is given as circles and the standard deviation for the imaginary part of the impedance is given as triangles. The standard deviation is seen to be a small percentage of the modulus, ranging from about $0.2 \%$ at low frequency to about $0.02 \%$ at high frequency. This standard deviation $\sigma$ is the error structure used to weight regressions and must be determined for each type of experiment.

The application of the Kramers-Kronig integrals to impedance data was considered controversial in the late $20^{\text {th }}$ century because the integrand included an interpolated function of frequency ranging from zero to infinity, requiring extrapolation into the unmeasured frequency domain (see Box 1). This objection was resolved by the regression of a measurement model to the data. This measurement model (Fig. 9a) satisfied the Kramers-Kronig relations and was shown to provide a satisfactory fit to the impedance data, which supports that data fit by the measurement model could be understood to be consistent with the Kramers-Kronig relations. ${ }^{72}$ Most vendors of impedance instrumentation provide a regression-based assessment of the consistency with the Kramers-Kronig relations that is derived from a linear measurement model analysis. ${ }^{125}$ The nonlinear Voigt measurement model approach described here has greater sensitivity to inconsistency with the Kramers-Kronig relations, making it easier to identify frequencies for which a given data set does not satisfy the Kramers-Kronig relations. ${ }^{126}$

\section{[H1] LIMITATIONS AND OPTIMIZATIONS}

The set of measured signals in CV and EIS contain the same information, which should be easy to deconvolute depending on the physicochemical process and whether CV or EIS is used. Nevertheless, it is sometimes difficult to compare results obtained from both techniques. Currently, the evaluation of interfacial capacitance from CV and EIS for the case of a non-ideal behaviour, ${ }^{127-130}$ which is commonly depicted as a CPE, remains an unresolved issue. The CPE is considered to result from a position-dependent distribution of a time constant, represented as $\tau(x)=R(x) C(x),{ }^{134}$ and is often used in an electrical 
circuit model to improve the fitting to the impedance data (see Box 3). The distribution of time constant along the surface of the electrode may be caused by the variation in surface distribution of current and potential due to the electrode geometry. The time constant distribution may also be in the direction normal to the electrode as a result of a distribution of properties for an oxide or polymeric film. In principle, the interfacial capacitance obtained by EIS and CV for the same system should be the same, but that equality has not yet been demonstrated experimentally. Both techniques are in situ and measure a total current and an averaged potential. However, CV measures the global effective observation of the CPE behaviour over a broad range of potential; whereas EIS provides a measurement at a specified potential.

Analytical electrochemistry experiments usually employ disk electrodes that are studied by means of a classical three-electrode potentiostat and a frequency response analyzer for measuring the impedance response. A three-electrode device enables monitoring the electrochemical processes occurring only at the working electrode, dissociating them from the processes taking place at the counter-electrode. However, even with these simple systems, the impedance response is not trivial. The observed EIS response depends on the electrochemical reactions at the working electrode, the geometry of the cell as well as the electrode and the electrolyte conductivity, which often results in a non-ideal response of the interfacial capacitance. ${ }^{54,131-134}$ Independent of this frequency dispersion that is ascribed to the cell geometry and that gives rise to a high-frequency ohmic impedance, ${ }^{54}$ the capacitive behaviour of the interface is rarely ideal and requires the use of a CPE for its description. ${ }^{93,135,136}$ Also, commercial reference electrodes usually have high impedance that leads to high frequency artifacts, but this drawback can be overcome by using a dual reference electrode..$^{57}$ Overall, the measured electrochemical impedance depends on the mechanism under investigation in addition to the extrinsic parameters that are not associated with the mechanism, such as the geometry of the cell and the electrode.

Some systems are inherently more complex. For example, the study of corrosion ${ }^{137,138}$ or corrosion protection ${ }^{139,140}$ systems using coatings have small current densities, and thus require measurements using large electrodes. ${ }^{141,142}$ Measurements on batteries are most often performed on two-electrode systems. The contributions of both electrodes are then measured simultaneously, which makes the analysis of the response even more complex because it includes the sum of the positive and negative electrode contributions. This experimental difficulty can be circumvented by inserting a reference electrode in the device ${ }^{46,143,144}$ or using a symmetric cell. ${ }^{145,146}$ Other artifacts may exist, such as an inductive contribution caused by the connecting wires in the high-frequency domain when low 
impedances are measured (for batteries applications) or a significant noise in the low-frequency range when measuring high impedance (for anti-corrosion coatings). In the latter case, a potentiostat that allows the measurement of small currents must be used and the measurement must be carried out in a Faraday cage. A simple way to eliminate measurement errors related to the equipment is to perform the same measurement on an equivalent electrical circuit exhibiting similar characteristics (time constants and impedance magnitude) as the electrochemical system under study.

Different techniques have been developed to perform impedance measurements with respect to instrumentation, where the most common one is the FRA ${ }^{4}$. However, other approaches such as the use of multisine, ${ }^{69,147,148}$ white noise ${ }^{149,150}$ or wavelet ${ }^{151,152}$ are also used, but their description is outside the scope of this Primer. These techniques have also been used to evaluate other transfer functions involving electrochemical systems such as thermal impedance spectroscopy, ${ }^{153}$ electrohydrodynamic impedance ${ }^{154-}$ ${ }^{156}$, modulation of the interfacial capacitance ${ }^{157-160}$ and local electrochemical impedance spectroscopy. ${ }^{161-}$ 165

\section{[H2] FIELD-SPECIFIC LIMITATIONS}

A general purpose EIS module may not have adequate accuracy for the test sample one wants to measure and depending on the application of EIS different issues are likely to arise.

\section{[H3] LOW-FREQUENCY RANGE}

For measurement at low frequency, the major problem is the long measurement time and the drifting or non-stationarity of the system. The lower the frequency, the more pronounced this problem is. The multi-sine method has been proposed to alleviate the problem by reducing the measurement time, ${ }^{166}$ but the result represents an averaged behaviour that is always consistent with the Kramers-Kronig relations. ${ }^{126}$ Thus, the Kramers-Kronig relations cannot be used to detect the influence of nonstationary behaviour on multi-sine measurements.

In lithium-ion batteries, potentiostatic EIS at low frequency will involve the charging and discharging of the cell, revealing a capacitive behaviour. ${ }^{167}$ For galvonostatic EIS, the cell is under charging or discharging, hence non-stationary conditions, violating one of the three prerequisites for impedance. However, continuous efforts to measure the EIS of a non-stationary system, frequently under the rubric of dynamic EIS, have been reported over the years. Following the first report of studying a non-stationary system in $1985^{; 168}$ a proposed time correction method was used to study rechargeable lithium ion batteries ${ }^{169}$ and criterion for the restriction on the amplitude was explored in a discharging/charging process. ${ }^{170}$ 
For proton-exchange membrane fuel cells (PEMFCs), additional features appear at low frequencies with controversial explanations. For example, inductive loops attributed to different mechanisms, such as humidity dependent ionomer properties, ${ }^{171}$ poisoning of Pt oxide growth ${ }^{172}$ or relaxation of intermediate adsorbed species in multi-step ORR reaction, are observed in the low frequency range. ${ }^{173}$ However, the dominant mechanism for these inductive loops may vary with working condition. The lower the humidity, the more significant the effect of water transport across the membrane; the higher the potential, the greater the effect of Pt oxide formation and intermediate species adsorption. In a distributed EIS measurement, local EIS at downstream even ventured into the second quadrant (negative real and negative imaginary), a peculiar behaviour that is associated with the consumption and interaction of $\mathrm{O}_{2}$ along the channel ${ }^{174}$. Dedicated complementary observations are needed to prove or disprove the proposed mechanisms and the conjecture that the dominant mechanism may vary with working condition.

\section{[H3] REFERENCE ELECTRODES}

Reversible hydrogen electrodes and dynamic hydrogen electrodes ${ }^{47}$ are employed as reference electrodes in PEMFCs. The tip of the reference electrode is usually located outside the active area, ${ }^{175}$ due to the narrow space $(\sim 10 \mu \mathrm{m})$ between the anode and cathode. In coin cells or pouch-type lithium-ion batteries, reference electrodes are either placed between the electrodes or outside the active area of the electrodes. ${ }^{176}$ Although artifacts such as current leaking and short circuit have been associated with placing the lithium metal reference electrode between the two electrodes. ${ }^{177}$ For durable use of reference electrodes in lithium-ion batteries, in-situ electrochemical alloying a thin insulated gold wire with lithium ${ }^{178}$ and plating Li in nickel mesh ${ }^{179}$ are a couple of potential routes. Such reference electrodes can last reliably for months, which is extremely valuable for diagnosing cells under cycling.

\section{[ H1] OUTLOOK}

The development of EIS over the past decades has enabled a better understanding of many electrochemical systems involved in our modern technologies. The versatility of EIS and its ability to retrieve in situ quantitative information from complex electrochemical systems has made it an essential and complementary tool for electrochemists. However, careful considerations on the choice of experimental conditions and appropriate mathematical models that would accurately describe the physics and reactions mechanisms involved in the system considered are necessary. EIS is used as a routine tool for electrochemical characterization, however, the analysis is often limited to regression of equivalent electrical circuits ${ }^{180}$. 
Since the 1980s, the EIS technique has benefited from substantial advances in electronic instrumentation that have facilitated impedance measurements. These advances will continue, often with specific objectives such as enabling measurement of local electrochemical impedance or coupling EIS with other transfer-function measurements. Different routes can be considered to measure the local impedance. The use of a bi-electrode allows these measurements, but the spatial resolution is currently limited to about $1 \mu \mathrm{m}$. Optical measurements provide an interesting way to improve this resolution, but they are limited to an interface whose topography does not change with time, which is thus not suitable for the study of many systems such as corroding materials or for systems that experience volume changes as a function of their state of charge such as battery materials. The use of multiple transfer functions combining the traditional electrochemical measurement with that of one or more other parameters such as temperature, pressure, or hydrodynamic conditions of the solution is another area of development.

The analysis and interpretation of the large quantities of impedance data that can be generated in a laboratory or industrial setting is another area of interest. Automated circuit modeling of impedance data has been proposed, but circuit models obscure the underlying physics and chemistry. In particular, impedance models are not unique and EIS is not a stand-alone technique. Hypothesis-driven models can guide selection of complementary experiments that can be used to allow the user to gain confidence in their model or disprove it.

Interpretation of impedance measurements requires both a model that accounts for the chemistry and physics of the system under study and the error structure of the data. The quality of the measurement may be assessed using various approaches. The stochastic and bias contributions to the error structure may be identified by use of recently published software. ${ }^{73}$ Manufacturers of impedance instrumentation are urged to include estimates of the standard deviation of impedance measurement as part of their standard output, and researchers are encouraged to consider sample-to-sample variability when appropriate. Overall, verifying the consistency of analyzed data with the Kramers-Kronig relations should become a standard for publication of impedance data.

EIS data interpretation will move in two major directions. The first is the rapid automated interpretation of data, which can be quantitative if driven by a solid understanding of the system under study, but is otherwise a qualitative assessment. The other direction includes a more systematic analysis that sees EIS as one of a set of complementary tools that can be used to explore the physics and chemistry of electrochemical systems. ${ }^{97}$ The automated interpretation will facilitate use of impedance for diagnostics such as understanding the health of batteries in electric vehicles, enhancing signal processing 
for subcutaneous glucose sensors or for rapid processing of data collected from multichannel test stations. The system-specific modeling will enhance the ability of research labs to understand the broad range of systems for which EIS may be used. 


\section{FIGURE CAPTIONS}

Figure 1. Required steps to acquire an electrochemical impedance spectroscopic measurement. This includes an electrochemical system (a) with a working electrode (WE), a counter electrode (CE), and a reference electrode $(\mathrm{RE})$. In this example, a periodic perturbation signal $(\Delta \mathrm{E})$ is applied between WE and RE from high to low frequencies (b), and the electrochemical response to this perturbation is measured in the linear domain (c). Impedance data are often presented in Nyquist or Bode representations (d) and may be represented by an equivalent circuit in which a mechanistic interpretation of the system under study is used to extract a meaning for the faradaic impedance $Z_{F}(e)$.

Figure 2. Guidelines for EIS measurements. a) Schematic representation of the two-electrode setup. b) Schematic representation of the three-electrode setup; c) schematic representation of the four-electrode setup, where WE is the working electrode, WSE is working sense electrode, RE is the reference electrodes, and $C E$ is the counter electrode. d) Accuracy contour plot in which line $A$ is the maximum measurable impedance, $B$ is the capacitive limit, $C$ is the maximum measurable frequency, $D$ is the inductive limit, and $E$ is the lowest measurable impedance. e) Circuit representation showing the influence of wire capacitance, resistance, and inductance on the measured impedance. For most measurements, the contribution of wire properties can be neglected, and measured impedance is the same as the cell impedance. Acceptable measurements may be made in the region with $<1 \%$ error in magnitude and $<2^{\circ}$ error in phase. Measurements in the region marked $>10 \%,>10^{\circ}$ will show anomalous features caused by the instrument and cabling. f) Schematic representation of a wire connection to the electrochemical cell, where $V_{1}$ and $V_{2}$ are the voltage connectors, and $A_{1}$ and $A_{2}$ are the current connectors; g) twisted wires suppress mutual induction.

Figure 3. EIS data of an ideally polarizable electrode obtained for a redox couple in solution. a) Temporal measurements of potential and current as a function of time at frequency of $20 \mathrm{~Hz}$ where the red line is current density and the blue line is potential, b) Lissajous curve (current as function of potential) plotted from the results presented in (a), c) Bode representation - modulus and phase of impedance as a function of the frequency, d) Nyquist representation - imaginary part of impedance as a function of the real part in a complex plane with frequency as a parameter, e) representation of a mass-transfer controlled electrochemical reaction involving an oxidized species $O x$ and a reduced species Red, f) cyclic voltammetry with scan rate as a parameter, and g) chronoamperometry with time in a linear and logarithmic (inset plot) scale. All these results shown in (f) and (g) were obtained for the same set of parameters for a planardisk electrode $\left(A=0.2 \mathrm{~cm}^{2}\right)$ under assumption of a Butler-Volmer relationship for a quasi-reversible process with semi-infinite diffusion: $\mathrm{k}^{0}=10^{-2} \mathrm{cms}^{-1} ; \alpha=0.5 ; \mathrm{E}^{0}=-0.1 \mathrm{~V} / \mathrm{NHE} ; D_{\text {ox }}=D_{\text {red }}=10^{-5} \mathrm{~cm}^{2} \mathrm{~s}^{-1}$; $\mathrm{C}_{\mathrm{ox}}{ }^{*}=10 \mathrm{mM} ; \mathrm{C}_{\mathrm{red}}{ }^{*}=0 \mathrm{mM} ; \mathrm{R}_{\mathrm{e}}=5 \Omega ; \mathrm{C}_{\mathrm{dl}}=10 \mu \mathrm{F}$.

Figure 4. Sample analysis of impedance data. a) Impedance data in a Nyquist format for reduction of ferricyanide on a $5 \mathrm{~mm}$ diameter Pt disk rotating at $120 \mathrm{rpm}$ after $14 \mathrm{~s}, 32135 \mathrm{~s}, 33305 \mathrm{~s}$ and $34472 \mathrm{~s}$. The lines represent the weighted fit of equation (7) to the data. The difference between the first measurement $(14 \mathrm{~s})$ and measurements taken after 8.93 hours can be attributed to the slow formation of a film on the 
electrode surface. b) Electrical circuit corresponding to convective diffusion to a rotating disk electrode with high-frequency CPE behaviour where $R_{\mathrm{e}}$ is the ohmic resistance, $R_{\mathrm{t}}$ is the charge-transfer resistance associated with electrode kinetics, $a$ and $Q$ are parameters associated with the CPE, and $Z_{\mathrm{D}}$ is the diffusion impedance associated with transport of reactive species to the electrode surface. The graph generated in panel a uses data reported in reference 91.

Figure 5. Typical EIS spectra and the corresponding physical processes. a) iron corrosion in sulfuric acid solution, ${ }^{94}$ b) solid oxide fuel cells, ${ }^{95}$ c) lithium-ion batteries, ${ }^{79}$ and d) polymer electrolyte fuel cells. The circled numbers in Figures 5b, 5c, and $5 d$ refer to transport and reaction mechanisms and their influence on the respective Nyquist plots. Panel $a$ is adapted with permission from ref 94, IOP. Panel $b$ is adapted with permission from ref 95, RSC. Panel $c$ is adapted with permission from ref 79, IOP.

Figure 6. The use of EIS measurements at different temperatures to extract activation energy. a) The current-overpotential curve for electrochemical systems showing the relationship between exchange current to the slope of the current-potential plot and b) the activation energy is obtained from the slope of the exchange current density as a function of inverse absolute temperature. The charge-transfer resistance is obtained from the high-frequency loop of the inset impedance diagram. ${ }^{110}$ Panels $a$ and $b$ adapted with permission from ref 109, Elsevier.

Figure 7. Use of EIS to detect the concentration of breast cancer cells. This was achieved via covalent grafting of the specific antibody directed against the receptor anti c-erbB-2 on electrogenerated polymers: a) EIS of system with MCF-7 cancer cells ${ }^{116}$ where (1) 0 cell/mL, (2) 100 cell/mL, (3) 1000 cell/mL, (4) 10000 cell/mL, (5) $100000 \mathrm{cell} / \mathrm{mL}$ and b) evolution of the resistance change as compared to case i, $\Delta R_{2}$, as a function of the concentration of MCF-7 cancer cell. Error bars show the relative standard deviation $(\mathrm{RSD}=5 \%)$ of three identical experiments. Panels $a$ and $b$ adapted with permission from ref 116 , Elsevier.

Figure 8. Influence of pore size distribution on impedance behavior. a) Impedance of porous materials with various pore size distributions, ${ }^{119,120}$ where $R_{\text {pore }}$ is the pore resistance, and $\mathrm{b}$ ) corresponding pore size distribution of porous materials where $\bar{r}$ is the average radius and $\sigma$ is the standard deviation of the radius distribution. Panels $a$ and $b$ adapted with permission from ref 119 , Elsevier.

Figure 9. Measurement model analysis to identify the error structure of impedance data. a) Schematic representation of a Voigt circuit used as a measurement model. ${ }^{181}$ To improve the stability of the regressions, the model, as shown in equation (14), is written in terms of resistors and time constants. Taken from Liao, et al. ${ }^{182}$ The Voigt measurement model may be used to assess the error structure of impedance measurements and to provide preliminary physical properties such as ohmic resistance and capacitance. b) The standard deviation of the stochastic part of the error structure for the data presented in Figure 7. The measurement model approach was used to filter lack of replication in repeated measurements. Panel a adapted with permission from ref 181, Elsevier. 


\section{TABLES}

Table 1: Results from the weighted regression of equation (7) to the sample data presented in Fig. 7. Confidence intervals given are $\pm 1 \sigma$. The $\chi^{2} / v$ statistic should be on the order of unity for a perfect regression. These results show that the model could be further improved. The effective capacitance and characteristic frequency were calculated from the regressed parameters. The current and potential were measured after each EIS measurement.

\begin{tabular}{|c|c|c|c|c|}
\hline $\begin{array}{l}\text { Parameters } \\
\text { (units) }\end{array}$ & $14 \mathrm{~s}$ & $32135 \mathrm{~s}$ & $33305 \mathrm{~s}$ & $34472 \mathrm{~s}$ \\
\hline Sc & $1076 \pm 14$ & $1235.7 \pm 7.8$ & $1244.8 \pm 8.0$ & $1256.5 \pm 8.3$ \\
\hline$R_{e}\left(\Omega \mathrm{cm}^{2}\right)$ & $1.252 \pm 0.072$ & $1.381 \pm 0.011$ & $1.383 \pm 0.011$ & $1.382 \pm 0.011$ \\
\hline$Q\left(\mu F s^{\alpha-1} \mathrm{~cm}^{-2}\right)$ & $460 \pm 68$ & $59.8 \pm 1.2$ & $59.4 \pm 1.2$ & $59.6 \pm 1.3$ \\
\hline$R_{d}\left(\Omega \mathrm{cm}^{2}\right)$ & $31.719 \pm 0.066$ & $33.199 \pm 0.031$ & $33.289 \pm 0.032$ & $33.390 \pm 0.033$ \\
\hline$R_{t}\left(\Omega \mathrm{cm}^{2}\right)$ & $1.273 \pm 0.078$ & $3.137 \pm 0.013$ & $3.161 \pm 0.013$ & $3.188 \pm 0.013$ \\
\hline$\alpha$ & $0.702 \pm 0.026$ & $0.9048 \pm 0.0 .0028$ & $0.9057 \pm 0.0 .0028$ & $0.9052 \pm 0.0 .0029$ \\
\hline$\chi^{2}(v)$ & 139 & 53 & 56 & 59 \\
\hline$C\left(\mu \mathrm{F} \mathrm{cm}{ }^{-2}\right)$ & 14.4 & 21.4 & 21.5 & 21.4 \\
\hline$f_{c}(k H z)$ & 8.8 & 5.4 & 5.4 & 5.4 \\
\hline Current (mA) & 90.3 & 91.3 & 91.3 & 90.2 \\
\hline Potential(mV) & 215.6 & 215.7 & 215.7 & 215.7 \\
\hline
\end{tabular}




\section{BOXES}

\section{[BH1] BOX 1. KRAMERS KRONIG TRANSFORMATIONS}

The Kramers-Kronig transformations were derived under the assumptions that a system is: stable such that perturbations to the system do not grow; responds linearly to a perturbation; and is causal where a response to a perturbation cannot precede the perturbation. These relations are widely used as part of a validation procedure to identify the frequency ranges that may have been corrupted by instrument artifacts or by nonstationary behavior.

The imaginary part of the impedance can be calculated from the real part through:

$$
Z_{j}(\omega)=-\frac{2 \omega}{\pi} \int_{0}^{\infty} \frac{Z_{r}(x)-Z_{r}(\omega)}{x^{2}-\omega^{2}} d x
$$

If the high-frequency limit of the impedance is known $\left(Z_{r}(\infty)\right)$, the real part can be obtained from the imaginary part through:

$$
Z_{r}(\omega)=Z_{r}(\infty)+\frac{2}{\pi} \int_{0}^{\infty} \frac{x Z_{j}(x)-\omega Z_{j}(\omega)}{x^{2}-\omega^{2}} d x
$$

Direct integration of the Kramers-Kronig relations for EIS measurements has been replaced, in modern use, by regression of Kramers-Kronig-consistent circuit models that provide extrapolation to zero and infinite frequency limits that is consistent with the behavior of electrochemical systems. 


\section{[BH1] BOX 2. LINEARITY, STABILITY AND CAUSALITY}

\section{[BH2] LINEARITY}

The constraint of linearity means that the response to an input perturbation is a linear function of the single- or multi-frequency input. Because the current is a nonlinear function of potential for electrochemical systems, linearity is achieved by using a small input perturbation such that the current can be expressed by the first term of its Taylor series expansion. The choice of an input perturbation magnitude is a compromise between the need to achieve linearity and the need for a sufficient signal-tonoise ratio.

\section{[BH2] STABILITY}

The constraint of stability means that the response to a perturbation cannot grow with time. The current response to a step in potential must eventually decay to a new steady value.

\section{[BH2] CAUSALITY}

The constraint of causality means that the response to a perturbation cannot precede the perturbation. This constraint ensures that the measured AC-response of the system to an external modulation must be correlated only to the applied AC perturbation. Causality is especially important for electrochemical systems because measurements can take minutes to hours, depending on the frequency range used, and non-stationary behavior leads to failure of causality. 
The CPE is often used to improve the fit of models to impedance data. The CPE parameters $\alpha$ and $Q$ cannot be used directly to extract a capacitance; however, a capacitance may be extracted under assumption of a distribution of time constants along the electrode surface or through a film. Not all time-constant distributions give rise to a CPE. The ohmic-resistance-corrected phase angle provides a convenient way to determine if a time-constant distribution is represented by a CPE. 


\section{GLOSSARY}

Capacitance: the ability of the electrochemical system, specifically the electrode-electrolyte interface, to hold electrical charge. $\left(\mathrm{F} \mathrm{m}^{-2}\right)$

Chronoamperometry: Electrochemical technique in which a potential step is applied to a working electrode and the current response is recorded as a function of time.

Chronopotentiometry: Electrochemical technique in which a current step is applied to a working electrode and the potential response is recorded as a function of time.

Complex number: ordered pair of real and imaginary numbers.

Cyclic voltammetry: Electrochemical technique in which the current response of an electrochemical system is measured as a function of the potential, which is swept in positive and negative directions at a given rate.

Frequency decade: a unit for measuring frequency ratios on a logarithmic scale, with one decade corresponding to a ratio of 10 between two frequencies (an order of magnitude difference).

Interfacial capacitance: capacity of the electrical double layer or the double layer in series with a thin film on the electrode surface. $\left(\mathrm{F} \mathrm{m}^{-2}\right)$

Levenberg-Marquardt regression: a mathematical algorithm used to solve non-linear least squares curve-fitting problems that is sensitive to initial values and provides confidence intervals for the resulting parameter estimates.

Ohmic resistance: an ionic resistance of the electrolyte and electronic resistance of the electrode, wire and connection $\left(\Omega \mathrm{m}^{2}\right)$

Oscilloscope: an electronic hardware monitoring the time-domain signals that are processed in the impedance measurement (for example, Lissajous plot).

Potentiostat: electronic hardware for electrochemical experiments maintaining a constant potential difference between the working electrode and the reference electrode.

Reactance: imaginary part of the impedance of an electrical circuit $\left(\Omega \mathrm{m}^{2}\right)$

Resistance: real part of the impedance of an electrical circuit $\left(\Omega \mathrm{m}^{2}\right)$

Rotating Disk Electrode: setup allowing the control of the rotation rate of a disk electrode embedded in an insulating circular plane in order to enhance and tune mass transport by generating a thin diffusion layer with uniform thickness.

Scanning electrochemical microscopy: local electrochemical technique that allows for sensing the surface topography and reactivity

Simplex regression: a robust mathematical algorithm used to solve non-linear least squares curve-fitting problems that is less sensitive to initial values but does not provide confidence intervals for the resulting parameter estimates. 
Warburg semi-infinite diffusion impedance: an impedance element describing the diffusion behaviour of the electrolyte in the absence of convection with a diffusion layer that can spread to the infinity. 


\section{REFERENCES}

1 Bard, A. J. \& Faulkner, L. R. Electrochemical Methods: Fundamentals and Applications. Second edn, (John Wiley \& Sons 2001).

2 Orazem, M. E. \& Tribollet, B. Electrochemical Impedance Spectroscopy. Second edn, (Wiley, 2017).

\section{A good introduction to hypothesis-driven modeling of impedance spectroscopy.}

3 Macdonald, D. D. Transient Techniques in Electrochemistry. (Plenum Press, 1977).

4 Gabrielli, C. Identification of electrochemical process by frequency response analysis. (The Solartron lectronic Group 1980).

5 Barsoukov, E. \& Macdonald, J. R. Impedance Spectroscopy: Theory, Experiment, and Applications. Second edn, (John Wiley \& Sons, 2005).

6 Deleebeeck, L. \& Veltze, S. Electrochemical impedance spectroscopy study of commercial Li-ion phosphate batteries: A metrology perspective. Int J Energ Res 44, 7158-7182, doi:10.1002/er.5350 (2020).

7 Bredar, A. R. C., Chown, A. L., Burton, A. R. \& Farnum, B. H. Electrochemical Impedance Spectroscopy of Metal Oxide Electrodes for Energy Applications. Acs Appl Energ Mater 3, 66-98, doi:10.1021/acsaem.9b01965 (2020).

$8 \mathrm{Xu}, \mathrm{Y}$. et al. A review of impedance measurements of whole cells. Biosensors and Bioelectronics 77, 824-836, doi:10.1016/j.bios.2015.10.027 (2016).

9 Bahadir, E. B. \& Sezgintürk, M. K. A review on impedimetric biosensors. Artificial Cells, Nanomedicine and Biotechnology 44, 248-262, doi:10.3109/21691401.2014.942456 (2016).

10 Bandarenka, A. S. Exploring the interfaces between metal electrodes and aqueous electrolytes with electrochemical impedance spectroscopy. Analyst 138, 5540-5554, doi:10.1039/c3an00791j (2013).

11 Sacco, A. Electrochemical impedance spectroscopy: Fundamentals and application in dyesensitized solar cells. Renewable and Sustainable Energy Reviews 79, 814-829, doi:10.1016/j.rser.2017.05.159 (2017). Margarit-Mattos, I. C. P. EIS and organic coatings performance: Revisiting some key points. Electrochim. Acta 354, 136725, doi:10.1016/j.electacta.2020.136725 (2020).

13 Macdonald, D. D. Reflections on the history of electrochemical impedance spectroscopy. Electrochim Acta 51, 1376-1388 (2006).

14 Gabrielli, C. Once upon a time there was EIS. Electrochim. Acta 331, 135324, doi:10.1016/j.electacta.2019.135324 (2020).

\section{A detailed description of the EIS history, especially the evolution of EIS measurement} equipment.

Kohlrausch, F. \& Nippoldt, W. A. Ueber die Gültigkeit der Ohm'schen Gesetze für Elektrolyte und eine numerische Bestimmung des Leitungswiderstandes der verdünnten Schwefelsäure durch alternirende Ströme. Annalen der Physik 214, 280-298, doi:10.1002/andp.18692141006 (1869). Kohlrausch, F. Ueber die elektromotorische Kraft sehr dünner Gasschichten auf Metallplatten. Annalen der Physik 224, 143-154, doi:10.1002/andp.18732240110 (1873). Wien, M. Ueber die Polarisation bei Wechselstrom. Annalen der Physik 294, 37-72, doi:10.1002/andp.18962940504 (1896). Warburg, E. Ueber die Polarisationscapacität des Platins. Ann. Phys.-Berlin 311, 125-135, doi:10.1002/andp.19013110910 (1901). 
Hickling, A. Studies in electrode polarisation. Part IV.-The automatic control of the potential of a working electrode. Transactions of the Faraday Society 38, 27-33, doi:10.1039/TF9423800027 (1942).

20 Koutecky, J. \& Levich, V. G. The use of a rotating disk electrode in the study of electrochemical kinetics and electrolytic processes. Zh. Fiz. Khim. 32, 1565-1575 (1958).

21 de Levie, R. On porous electrodes in electrolyte solutions: I. Capacitance effects. Electrochim. Acta 8, 751-780, doi:https://doi.org/10.1016/0013-4686(63)80042-0 (1963).

22 de Levie, R. On porous electrodes in electrolyte solutions-IV. Electrochim. Acta 9, 1231-1245, doi:10.1016/0013-4686(64)85015-5 (1964).

23 Gerischer, H. \& Mehl, W. Zum Mechanismus der kathodischen Wasserstoffabscheidung an Quecksilber, Silber und Kupfer. Zeitschrift für Elektrochemie, Berichte der Bunsengesellschaft für physikalische Chemie 59, 1049-1059, doi:10.1002/bbpc.19550591031 (1955).

24 Gerischer, H. Intermediates in electrochemical reactions. Faraday Discussions of the Chemical Society 56, 7-15, doi:10.1039/dc9735600007 (1973).

25 Klahr, B., Gimenez, S., Fabregat-Santiago, F., Hamann, T. \& Bisquert, J. Water oxidation at hematite photoelectrodes: the role of surface states. J. Am. Chem. Soc. 134, 4294-4302, doi:10.1021/ja210755h (2012).

26 Wang, H., Guerrero, A., Bou, A., Al-Mayouf, A. M. \& Bisquert, J. Kinetic and material properties of interfaces governing slow response and long timescale phenomena in perovskite solar cells. Energy \& Environmental Science 12, 2054-2079, doi:10.1039/c9ee00802k (2019).

A comprehensive review on perovskite solar cells, with emphasis on the use of impedance spectroscopy for studying kinetics of bulk and interface processes.

27 Epelboin, I., Gabrielli, C., Keddam, M. \& Takenouti, H. Model of the anodic behavior of iron in sulfuric acid medium. Electrochim. Acta 20, 913-916, doi:10.1016/0013-4686(75)87017-4 (1975).

28 Keddam, M., Mattos, O. R. \& Takenouti, H. Reaction model for iron dissolution studied by electrode impedance. I. Experimental results and reaction model. J. Electrochem. Soc. 128, 257266, doi:10.1149/1.2127401 (1981).

A detailed description of the procedure to follow for EIS interpretation in the case of complex mechanisms using iron dissolution as an example.

29 Baril, G. et al. An impedance investigation of the mechanism of pure magnesium corrosion in sodium sulfate solutions. Journal of the Electrochemical Society 154, C108-C113 (2007).

30 Gomes, M. P. et al. On the corrosion mechanism of $\mathrm{Mg}$ investigated by electrochemical impedance spectroscopy. Electrochim. Acta 306, 61-70, doi:10.1016/j.electacta.2019.03.080 (2019).

31 de Levie, R. in Advances in Electrochemistry and Electrochemical Engineering, 6 329-397 (Eds P. Delahay, Ch.W. Tobias - Wiley New York, 1967).

The pioneering work in developing EIS model for porous electrode. Lasia, A. in Electrochemical Impedance Spectroscopy and its Applications York, 2014).

33 Lasia, A. Impedance of porous electrodes. J. Electroanal. Chem. 397, 27-33, doi:10.1016/00220728(95)04177-5 (1995).

34 Barcia, O. E. et al. Further to the paper "Application of the impedance model of de Levie for the characterization of porous electrodes" by Barcia et al. [Electrochim. Acta 47 (2002) 2109]. Electrochim. Acta 51, 2096-2097, doi:10.1016/j.electacta.2005.06.035 (2006).

35 Orazem, M. E. \& Tribollet, B. A tutorial on electrochemical impedance spectroscopy. ChemTexts 6, 12, doi:10.1007/s40828-020-0110-7 (2020).

36 Savéant, J. M. Elements of Molecular and Biomolecular Electrochemistry: An Electrochemical Approach to Electron Transfer Chemistry. (2006). 
37 Costentin, C., Drouet, S., Robert, M. \& Saveant, J. M. A Local Proton Source Enhances CO2 Electroreduction to CO by a Molecular Fe Catalyst. Science 338, 90-94 (2012).

38 Oleinick, A., Svir, I. \& Amatore, C. A few key theoretical issues of importance in modern molecular electrochemistry. Current Opinion in Electrochemistry 13, 33-39, doi:10.1016/j.coelec.2018.10.008 (2019).

39 Manbeck, G. F., Fujita, E. \& Concepcion, J. J. Proton-Coupled Electron Transfer in a Strongly Coupled Photosystem II-Inspired Chromophore-Imidazole-Phenol Complex: Stepwise Oxidation and Concerted Reduction. J. Am. Chem. Soc. 138, 11536-11549, doi:10.1021/jacs.6b03506 (2016).

40 Garreau, D., Saveant, J. M. \& Tessier, D. Potential Dependence of the Electrochemical TransferCoefficient - Impedance Study of the Reduction of Aromatic-Compounds. J. Phys. Chem. 83, 3003-3007 (1979).

41 Saveant, J. M. \& Tessier, D. Variation of the Electrochemical Transfer-Coefficient with Potential. Faraday Discussions 74, 57-72, doi:10.1039/dc9827400057 (1982).

42 Corrigan, D. A. \& Evans, D. H. Cyclic voltammetric study of tert-nitrobutane reduction in acetonitrile at mercury and platinum electrodes: Observation of a potential dependent electrochemical transfer coefficient and the influence of the electrolyte cation on the rate constant. J. Electroanal. Chem. 106, 287-304, doi:https://doi.org/10.1016/S00220728(80)80175-6 (1980).

43 Sluyters-Rehbach, M. Impedances of electrochemical systems: Terminology, nomenclature and representation - Part I: Cells with metal electrodes and liquid solutions (IUPAC

Recommendations 1994). Pure and Applied Chemistry 66, 1831-1891, doi:doi:10.1351/pac199466091831 (1994).

44 Newman, J. S. \& Thomas-Alyea, K. E. Electrochemical Systems. third edn, 647 (John Wiley \& Sons, 2004).

45 Bockris, J. O. M., Reddy, A. K. N. \& Gamboa-Aldeco, M. Modern Electrochemistry: Electrodics. second edn, Vol. 2A 764 (Kluver Academic Publishers, 2000).

46 Talaie, E. et al. Methods and protocols for electrochemical energy storage materials research. Chemistry of Materials 29, 90-105, doi:10.1021/acs.chemmater.6b02726 (2017).

47 Bard, A. J., Inzelt, G. \& Scholz, F. Electrochemical dictionary. (Springer Science \& Business Media, 2008).

48 Song, J. Y., Lee, H. H., Wang, Y. Y. \& Wan, C. C. Two- and three-electrode impedance spectroscopy of lithium-ion batteries. J. Power Sources 111, 255-267, doi:10.1016/s03787753(02)00310-5 (2002).

49 Engebretsen, E. et al. Localised electrochemical impedance measurements of a polymer electrolyte fuel cell using a reference electrode array to give cathode-specific measurements and examine membrane hydration dynamics. J. Power Sources 382, 38-44, doi:10.1016/j.jpowsour.2018.02.022 (2018).

50 Sone, Y., Ekdunge, P. \& Simonsson, D. Proton conductivity of Nafion 117 as measured by a fourelectrode AC impedance method. J. Electrochem. Soc. 143, 1254-1259, doi:10.1149/1.1836625 (1996).

51 Deslouis, C., Musiani, M. M. \& Tribollet, B. Free-standing membranes for the study of electrochemical reactions occurring at conducting polymer/electrolyte interfaces. J. Phys. Chem. 100, 8994-8999 (1996).

52 Keddam, M., Novoa, X. R. \& Vivier, V. The concept of floating electrode for contact-less electrochemical measurements: Application to reinforcing steel-bar corrosion in concrete. Corros. Sci. 51, 1795-1801, doi:10.1016/j.corsci.2009.05.006 (2009). 
53 Samec, Z. Electrochemistry at the interface between two immiscible electolyte solutions (IUPAC technical report). Pure and Applied Chemistry 76, 2147-2180, doi:10.1351/pac200476122147 (2004).

54 Huang, V. M.-W., Vivier, V., Orazem, M. E., Pebere, N. \& Tribollet, B. The apparent constantphase-element behavior of an ideally polarized blocking electrode a global and local impedance analysis. J. Electrochem. Soc. 154, C81-C88 (2007).

55 Shchukin, E., Vidensky, I. \& Petrova, I. J. J. o. m. s. Luggin's capillary in studying the effect of electrochemical reaction on mechanical properties of solid surfaces. 30, 3111-3114 (1995).

56 Newman, J. S. Resistance for Flow of Current to a Disk. J. Electrochem. Soc. 113, 501-502 (1966).

57 Tran, A. T., Huet, F., Ngo, K. \& Rousseau, P. Artefacts in electrochemical impedance measurement in electrolytic solutions due to the reference electrode. Electrochim. Acta 56, 8034-8039, doi:10.1016/j.electacta.2010.12.088 (2011).

A key paper on the way to circumvent the artefact linked to the reference electrode in the high frequency mode.

58 Hills, G. \& Payne, R. Improved method for measuring the double layer capacity at a dropping mercury electrode. Application to measurements at high pressure. Trans. Faraday Soc. 61, 316325 (1965).

59 Primer-EG, G, E. \& Lock-In, G.-A. (Princeton, 1986).

60 Wellstead, P. Frequency response analysis. (Solartron Instruments, 1983).

61 Pilla, A. A. A Transient Impedance Technique for the Study of Electrode Kinetics: Application to Potentiostatic Methods. J. Electrochem. Soc. 117, 467, doi:10.1149/1.2407544 (1970).

62 Itagaki, M., Ueno, M., Hoshi, Y. \& Shitanda, I. Simultaneous Determination of Electrochemical Impedance of Lithium-ion Rechargeable Batteries with Measurement of Charge-discharge Curves by Wavelet Transformation. Electrochim Acta 235, 384-389, doi:10.1016/j.electacta.2017.03.077 (2017).

63 instruments, G. Accuracy Contour Plots - Measurement and Discussion, $<$ https://www.gamry.com/application-notes/ElS/accuracy-contour-plots-measurement-anddiscussion/> (2020).

64 Zhong, G., Koh, C. K., Roy, K., leee \& leee. A twisted-bundle layout structure for minimizing inductive coupling noise. (leee, 2000).

65 Wojcik, P. T., Agarwal, P. \& Orazem, M. E. A method for maintaining a constant potential variation during galvanostatic regulation of electrochemical impedance measurements.

Electrochim. Acta 41, 977-983 (1996).

66 Wojcik, P. T. \& Orazem, M. E. Variable-amplitude galvanostatically modulated impedance spectroscopy as a tool for assessing reactivity at the corrosion potential without distorting temporal evolution of the system. Corrosion 54, 289-298, doi:10.5006/1.3284855 (1998).

Hirschorn, B., Tribollet, B. \& Orazem, M. E. On Selection of the Perturbation Amplitude Required to Avoid Nonlinear Effects in Impedance Measurements. Israel Journal of Chemistry 48, 133-142, doi:10.1560/ljc.48.3-4.133 (2008).

68 Hirschorn, B. \& Orazem, M. E. On the Sensitivity of the Kramers-Kronig Relations to Nonlinear Effects in Impedance Measurements. J. Electrochem. Soc. 156, C345-C351, doi:10.1149/1.3190160 (2009).

69 Van Ingelgem, Y., Tourwé, E., Blajiev, O., Pintelon, R. \& Hubin, A. Advantages of odd random phase multisine electrochemical impedance measurements. Electroanalysis 21, 730-739, doi:10.1002/elan.200804471 (2009).

70 Dokko, K. et al. Kinetic characterization of single particles of LiCoO2 by AC impedance and potential step methods. J. Electrochem. Soc. 148, A422 (2001). 
71 Agarwal, P., Crisalle, O. D., Orazem, M. E. \& Garcia-Rubio, L. H. Application of measurement models to impedance spectroscopy. II. Determination of the stochastic contribution to the error structure. J. Electrochem. Soc. 142, 4149-4158 (1995).

72 Agarwal, P., Orazem, M. E. \& Garcia-Rubio, L. H. Application of measurement models to impedance spectroscopy. III. Evaluation of consistency with the Kramers-Kronig relations. J. Electrochem. Soc. 142, 4159-4168 (1995).

An introduction to the use of Voigt measurement models to assess the consistency of impedance data to the Kramers-Kronig relations.

73 Watson, W. \& Orazem, M. E. Measurement Model Program. ECSArXiv, doi:https://doi.org/10.1149/osf.io/kze9x (2020).

74 Orazem, M. E., Pebere, N. \& Tribollet, B. Enhanced Graphical Representation of Electrochemical Impedance Data. Journal of the Electrochemical Society 153, B129-B136 (2006).

75 Ivers-Tiffée, E. \& Weber, A. Evaluation of electrochemical impedance spectra by the distribution of relaxation times. Journal of the Ceramic Society of Japan 125, 193-201, doi:10.2109/jcersj2.16267 (2017).

A significant contribution showing the interest of using the distribution function of relaxation times to identify the different time-constant of an EIS spectra.

76 Wan, T. H., Saccoccio, M., Chen, C. \& Ciucci, F. Influence of the Discretization Methods on the Distribution of Relaxation Times Deconvolution: Implementing Radial Basis Functions with DRTtools. Electrochim Acta 184, 483-499, doi:10.1016/j.electacta.2015.09.097 (2015).

77 Dierickx, S., Weber, A. \& Ivers-Tiffée, E. How the distribution of relaxation times enhances complex equivalent circuit models for fuel cells. Electrochim. Acta 355, 136764, doi:10.1016/j.electacta.2020.136764 (2020).

78 Nara, H., Yokoshima, T. \& Osaka, T. Technology of electrochemical impedance spectroscopy for an energy-sustainable society. Curr Opin Electroche 20, 66-77, doi:10.1016/j.coelec.2020.02.026 (2020).

79 Huang, J., Li, Z., Ge, H. \& Zhang, J. Analytical Solution to the Impedance of Electrode/Electrolyte Interface in Lithium-Ion Batteries. J. Electrochem. Soc. 162, A7037-A7048, doi:10.1149/2.0081513jes (2015).

80 Huang, J. \& Zhang, J. Theory of Impedance Response of Porous Electrodes: Simplifications, Inhomogeneities, Non-Stationarities and Applications. J. Electrochem. Soc. 163, A1983-A2000, doi:10.1149/2.0901609jes (2016).

A general framework of EIS models that can be applicable to the porous electrodes in LIB, fuel cell and capacitor.

81 Fuller, T. F., Doyle, M. \& Newman, J. Simulation and Optimization of the Dual Lithium Ion Insertion Cell. Journal of The Electrochemical Society 141, 1-10, doi:10.1149/1.2054684 (1994).

82 Gruet, D., Delobel, B., Sicsic, D., Lucas, I. T. \& Vivier, V. On the electrochemical impedance response of composite insertion electrodes - Toward a better understanding of porous electrodes. Electrochim. Acta 295, 787-800, doi:10.1016/j.electacta.2018.10.115 (2019).

83 Amatore, C. \& Maisonhaute, E. When voltammetry reaches nanoseconds. Anal. Chem. 77, 303A311A, doi:10.1021/ac053430m (2005).

84 Popkirov, G. S. \& Schindler, R. N. A New Impedance Spectrometer for the Investigation of Electrochemical Systems. Review of Scientific Instruments 63, 5366-5372, doi:Doi 10.1063/1.1143404 (1992).

85 Wiegand, G., Neumaier, K. R. \& Sackmann, E. Fast impedance spectroscopy: General aspects and performance study for single ion channel measurements. Rev Sci Instrum 71, 2309-2320, doi:10.1063/1.1150447 (2000). 
Macdonald, J. R., Schoonman, J. \& Lehnen, A. P. Applicability and power of complex nonlinear least squares for the analysis of impedance and admittance data. J. Electroanal. Chem. 131, 7795, doi:10.1016/0022-0728(82)87062-9 (1982).

87 ZPlot For Windows, http://www.scribner.com/software/146-zplot-and-zview-for-windows.

88 ZSimpWin, https://www.ameteksi.com/products/software/zsimpwin. Box, G. E. P. \& Draper, N. R. Empirical Model-Building and Response Surfaces. (Wiley, 1987). Draper, N. R. \& Smith, H., S. Applied Regression Analysis. (Wiley, 1981).

91 Orazem, M. E., Durbha, M., Deslouis, C., Takenouti, H. \& Tribollet, B. Influence of surface phenomena on the impedance response of a rotating disk electrode. Electrochim. Acta 44, 44034412, doi:Doi 10.1016/S0013-4686(99)00156-5 (1999).

92 Brug, G. J., van den Eeden, A. L. G., Sluyters-Rehbach, M. \& Sluyters, J. H. The Analysis of Electrode Impedances Complicated by the Presence of a Constant Phase Element. Journal of Electroanalytical Chemistry 176, 275-295 (1984).

93 Hirschorn, B. et al. Constant-Phase-Element Behavior Caused by Resistivity Distributions in Films: I. Theory. Journal of the Electrochemical Society 157, C452-C457 (2010).

94 Wu, S. L., Orazem, M. E., Tribollet, B. \& Vivier, V. The influence of coupled faradaic and charging currents on impedance spectroscopy. Electrochim Acta 131, 2-12 (2014). Gabrielli, C. \& Group, S. I. Identification of Electrochemical Processes by Frequency Response Analysis. (Solartron Electronic Group, 1980). Tuller, H. L., Litzelman, S. J. \& Jung, W. Micro-ionics: next generation power sources. Phys. Chem. Chem. Phys. 11, 3023-3034 (2009).

97 Huang, J. et al. Impedance Response of Porous Electrodes: Theoretical Framework, Physical Models and Applications. J. Electrochem. Soc. 167, doi:10.1149/1945-7111/abc655 (2020).

A systematic review of physics-based EIS models for porous electrodes with substantial mathematic details that may help model development.

98 Keddam, M., Mattos, O. R. \& Takenouti, H. Reaction model for iron dissolution studied by electrode impedance. II. Determination of the reaction model. J. Electrochem. Soc. 128, 266-274, doi:10.1149/1.2127402 (1981).

99 Pivac, I. \& Barbir, F. Inductive phenomena at low frequencies in impedance spectra of proton exchange membrane fuel cells - A review. J. Power Sources 326, 112-119, doi:https://doi.org/10.1016/i.jpowsour.2016.06.119 (2016).

100 Roy, S. K., Orazem, M. E. \& Tribollet, B. Interpretation of Low-Frequency Inductive Loops in PEM Fuel Cells. J. Electrochem. Soc. 154, doi:10.1149/1.2789377 (2007).

101 Huang, J. et al. An Analytical Three-Scale Impedance Model for Porous Electrode with Agglomerates in Lithium-Ion Batteries. J. Electrochem. Soc. 162, A585-A595, doi:10.1149/2.0241504jes (2015).

102 Sabet, P. S. \& Sauer, D. U. Separation of predominant processes in electrochemical impedance spectra of lithium-ion batteries with nickel-manganese-cobalt cathodes. J. Power Sources 425, 121-129 (2019).

103 Boillot, M. et al. Effect of gas dilution on PEM fuel cell performance and impedance response. Fuel cells 6, 31-37 (2006).

104 Harrington, D. A. \& Conway, B. E. AC IMPEDANCE OF FARADAIC REACTIONS INVOLVING ELECTROSORBED INTERMEDIATES .1. KINETIC-THEORY. Electrochim. Acta 32, 1703-1712, doi:10.1016/0013-4686(87)80005-1 (1987).

A systematic methodology to construct EIS models from multi-step reaction mechanism.

105 Epelboin, I., Keddam, M. \& Lestrade, J. C. Faradaic impedances and intermediates in electrochemical reactions. Faraday Discuss. Chem. Soc. 56, 264-275, doi:10.1039/dc9735600264 (1973). 
106 Gabrielli, C. \& Keddam, M. Heterogeneous reactions coupled by diffusion. Multiple stationary states, impedance, and stability. J. Electroanal. Chem. 45, 267-277 (1973).

107 Bertocci, U. \& Ricker, R. E. in ASTM Special Technical Publication.1154 edn 143-161.

108 Losiewicz, B., Jurczakowski, R. \& Lasia, A. Kinetics of hydrogen underpotential deposition at polycrystalline platinum in acidic solutions. Electrochim. Acta 80, 292-301, doi:10.1016/j.electacta.2012.07.019 (2012).

109 Wang, S. S., Sun, Y., Huang, F. S. \& Zhang, J. B. Freezing Site of Super-Cooled Water and Failure Mechanism of Cold Start of PEFC. Journal of the Electrochemical Society 166, F860-F864, doi:10.1149/2.0041913jes (2019).

110 Takahashi, M., Tobishima, S., Takei, K. \& Sakurai, Y. Reaction behavior of LiFePO4 as a cathode material for rechargeable lithium batteries. Solid State Ion. 148, 283-289, doi:10.1016/s01672738(02)00064-4 (2002).

111 Vieil, E., Maurey-Mey, M. \& Cauquis, G. Current log-transform vs reactant concentration as a tool for chemical reaction order and electrochemical mechanisms determination-I. General theory in steady-state voltammetry and application to electro-oxidation of thianthrene in presence of water. Electrochim. Acta 27, 1565-1583, doi:10.1016/0013-4686(82)80083-2 (1982).

112 Laidler, K. J. The development of the Arrhenius equation. Journal of Chemical Education 61, 494, doi:10.1021/ed061p494 (1984).

113 Hong, P., Xu, L. F., Jiang, H. L., Li, J. Q. \& Ouyang, M. G. A new approach to online AC impedance measurement at high frequency of PEM fuel cell stack. Int. J. Hydrog. Energy 42, 19156-19169, doi:10.1016/j.ijhydene.2017.06.035 (2017).

114 Zhu, J. G., Sun, Z. C., Wei, X. Z. \& Dai, H. F. A new lithium-ion battery internal temperature online estimate method based on electrochemical impedance spectroscopy measurement. J. Power Sources 274, 990-1004, doi:10.1016/j.jpowsour.2014.10.182 (2015).

115 Khan, M. Z. H., Hasan, M. R., Hossain, S. I., Ahommed, M. S. \& Daizy, M. Ultrasensitive detection of pathogenic viruses with electrochemical biosensor: State of the art. Biosens Bioelectron 166, 112431, doi:10.1016/j.bios.2020.112431 (2020).

116 Prodromidis, M. I. Impedimetric immunosensors-A review. Electrochim. Acta 55, 4227-4233, doi:10.1016/j.electacta.2009.01.081 (2010).

117 Seven, B. et al. Impedimetric biosensor for cancer cell detection. Electrochem. Commun. 37, 3639, doi:10.1016/j.elecom.2013.10.003 (2013).

118 Abe, T., Sagane, F., Ohtsuka, M., Iriyama, Y. \& Ogumi, Z. Lithium-ion transfer at the interface between lithium-ion conductive ceramic electrolyte and liquid electrolyte - A key to enhancing the rate capability of lithium-ion batteries. J. Electrochem. Soc. 152, A2151-A2154, doi:10.1149/1.2042907 (2005).

119 Song, H.-K., Jung, Y.-H., Lee, K.-H. \& Dao, L. H. Electrochemical impedance spectroscopy of porous electrodes: the effect of pore size distribution. Electrochim. Acta 44, 3513-3519 (1999).

120 Song, H.-K., Hwang, H.-Y., Lee, K.-H. \& Dao, L. H. The effect of pore size distribution on the frequency dispersion of porous electrodes. Electrochim. Acta 45, 2241-2257 (2000).

121 Suthar, B., Landesfeind, J., Eldiven, A. \& Gasteiger, H. A. Method to Determine the In-Plane Tortuosity of Porous Electrodes. Journal of the Electrochemical Society 165, A2008-A2018, doi:10.1149/2.0121810jes (2018).

122 Ritter, S. et al. Results of an international round-robin exercise on electrochemical impedance spectroscopy. Corrosion Engineering, Science and Technology, 1-15, doi:10.1080/1478422X.2020.1850070 (2020).

123 Tait, W. S. Using Electrochemical Measurements to Estimate Coating and Polymer Film Durability. Journal of Coatings Technology 75, 45-50 (2003). 
124 Tait, W. S. Using electrochemical measurements to estimate coating and polymer film durability. Journal of Coatings Technology 75, 45-50, doi:Doi 10.1007/Bf02730070 (2003).

125 Boukamp, B. A. A Linear Kronig - Kramers Transform Test for Immittance Data Validation. J. Electrochem. Soc. 142, 1885-1894, doi:10.1149/1.2044210 (1995).

126 You, C., Zabara, M. A., Orazem, M. E. \& Ulgut, B. Application of the Kramers-Kronig Relations to Multi-Sine Electrochemical Impedance Measurements. Journal of The Electrochemical Society 167, 020515, doi:10.1149/1945-7111/ab6824 (2020).

127 Allagui, A., Freeborn, T. J., Elwakil, A. S. \& Maundy, B. J. Reevaluation of Performance of Electric Double-layer Capacitors from Constant-current Charge/Discharge and Cyclic Voltammetry. Sci Rep 6, 38568, doi:10.1038/srep38568 (2016).

A detailed description of the use of a constant-phase element in cyclic voltammetry.

128 Gharbi, O., Tran, M. T. T., Tribollet, B., Turmine, M. \& Vivier, V. Revisiting cyclic voltammetry and electrochemical impedance spectroscopy analysis for capacitance measurements. Electrochim. Acta 343, 136109, doi:10.1016/j.electacta.2020.136109 (2020).

129 Sadkowski, A. Time domain responses of constant phase electrodes. Electrochim Acta 38, 20512054, doi:http://dx.doi.org/10.1016/0013-4686(93)80339-2 (1993).

130 Sadkowski, A. On the ideal polarisability of electrodes displaying cpe-type capacitance dispersion. J. Electroanal. Chem. 481, 222-226, doi:10.1016/s0022-0728(99)00480-5 (2000). This article discusses the physical meaning of constant phase element.

131 Newman, J. Frequency dispersion in capacity measurements at a disk electrode. Journal of the Electrochemical Society 117, 198-203 (1970).

132 Huang, V. M.-W., Vivier, V., Frateur, I., Orazem, M. E. \& Tribollet, B. The global and local impedance response of a blocking disk electrode with local constant-phase-element behavior. J. Electrochem. Soc. 154, C89-C98 (2007).

133 Huang, V. M.-W., Vivier, V., Orazem, M. E., Pebere, N. \& Tribollet, B. The apparent constantphase-element behavior of a disk electrode with Faradaic reactions. A global and local impedance analysis. J. Electrochem. Soc. 154, C99-C107 (2007).

134 Orazem, M. E. et al. Dielectric Properties of Materials Showing Constant-Phase-Element (CPE) Impedance Response. J. Electrochem. Soc. 160, C215-C225, doi:10.1149/2.033306jes (2013).

Overview of methods used to extract capacitance from CPE parameters, with emphasis on the use of a power-law model to extract thickness of oxide films.

135 Hirschorn, B. et al. Determination of effective capacitance and film thickness from constantphase-element parameters. Electrochim Acta 55, 6218-6227 (2010).

136 Hirschorn, B. et al. Constant-Phase-Element Behavior Caused by Resistivity Distributions in Films: II. Applications. Journal of the Electrochemical Society 157, C458-C463 (2010).

137 Díaz, B., Guitián, B., Nóvoa, X. R. \& Pérez, M. C. The effect of chlorides on the corrosion behaviour of weathered reinforcing bars. Electrochim. Acta 336, 135737, doi:10.1016/j.electacta.2020.135737 (2020).

138 Hernández, R. D. P. B., Aoki, I. V., Tribollet, B. \& De Melo, H. G. Electrochemical impedance spectroscopy investigation of the electrochemical behaviour of copper coated with artificial patina layers and submitted to wet and dry cycles. Electrochim Acta 56, 2801-2814, doi:10.1016/j.electacta.2010.12.059 (2011).

139 Capelossi, V. R. et al. Corrosion protection of clad 2024 aluminum alloy anodized in tartaricsulfuric acid bath and protected with hybrid sol-gel coating. Electrochim. Acta 124, 69-79, doi:10.1016/j.electacta.2013.09.004 (2014).

140 Bouali, A. C. et al. Layered double hydroxide based active corrosion protective sealing of plasma electrolytic oxidation/sol-gel composite coating on AA2024. Applied Surface Science 494, 829840, doi:10.1016/j.apsusc.2019.07.117 (2019). 
141 Calado, L. M., Taryba, M. G., Carmezim, M. J. \& Montemor, M. F. Self-healing ceria-modified coating for corrosion protection of AZ31 magnesium alloy. Corros Sci 142, 12-21, doi:10.1016/j.corsci.2018.06.013 (2018).

142 Roggero, A. et al. Thermal activation of impedance measurements on an epoxy coating for the corrosion protection: 2. electrochemical impedance spectroscopy study. Electrochim. Acta 305, 116-124, doi:10.1016/j.electacta.2019.03.007 (2019).

143 Karden, E., Buller, S. \& De Doncker, R. W. A method for measurement and interpretation of impedance spectra for industrial batteries. J. Power Sources 85, 72-78, doi:Doi 10.1016/S03787753(99)00385-7 (2000).

144 Costard, J., Ender, M., Weiss, M. \& Ivers-Tiffée, E. Three-Electrode Setups for Lithium-lon Batteries: II. Experimental Study of Different Reference Electrode Designs and Their Implications for Half-Cell Impedance Spectra. Journal of The Electrochemical Society 164, A80-A87, doi:10.1149/2.0241702jes (2017).

145 Osaka, T., Mukoyama, D. \& Nara, H. Review-Development of Diagnostic Process for Commercially Available Batteries, Especially Lithium Ion Battery, by Electrochemical Impedance Spectroscopy. J. Electrochem. Soc. 162, A2529-A2537, doi:10.1149/2.0141514jes (2015).

146 Itou, Y., Ogihara, N. \& Kawauchi, S. Role of Conductive Carbon in Porous Li-Ion Battery Electrodes Revealed by Electrochemical Impedance Spectroscopy Using a Symmetric Cell. J Phys Chem C 124, 5559-5564, doi:10.1021/acs.jpcc.9b11929 (2020).

$147 \mathrm{Ji}$, G., Macia, L. F., Allaert, B., Hubin, A. \& Terryn, H. Odd Random Phase Electrochemical Impedance Spectroscopy to Study the Corrosion Behavior of Hot Dip Zn and Zn-Alloy Coated Steel Wires in Sodium Chloride Solution. Journal of the Electrochemical Society 165, C246-C257, doi:10.1149/2.0741805jes (2018).

148 Sanchez, B., Fernandez, X., Reig, S. \& Bragos, R. An FPGA-based frequency response analyzer for multisine and stepped sine measurements on stationary and time-varying impedance. Measurement Science and Technology 25, doi:10.1088/0957-0233/25/1/015501 (2014).

149 Gabrielli, C., Huet, F. \& Keddam, M. Comparison of sine wave and white noise analysis for electrochemical impedance measurements. J. Electroanal. Chem. 335, 33-53, doi:10.1016/00220728(92)80230-2 (1992).

150 Chang, B. Y. \& Park, S. M. in Annual Review of Analytical Chemistry Vol. 3 207-229 (2010).

151 Smulko, J. M., Darowicki, K. \& Zielinski, A. On Electrochemical Noise Analysis for Monitoring of Uniform Corrosion Rate. IEEE Transactions on Instrumentation and Measurement 56, 20182023, doi:10.1109/TIM.2007.895624 (2007).

152 Cottis, R. A. Interpretation of electrochemical noise data. Corrosion 57, 265-285, doi:Doi 10.5006/1.3290350 (2001).

153 Abada, S. et al. Safety focused modeling of lithium-ion batteries: A review. J. Power Sources 306, 178-192, doi:10.1016/j.jpowsour.2015.11.100 (2016).

154 Deslouis, C., Tribollet, B., Mengoli, G. \& Musiani, M. M. Electrochemical behavior of copper in neutral aerated chloride solution. II. Impedance investigation. Journal of Applied Electrochemistry 18, 384-393, doi:10.1007/bf01093752 (1988).

A comprehensive analysis of EIS and transfer functions applied to the corrosion of copper in chloride solution.

155 Robertson, B., Tribollet, B. \& Deslouis, C. Measurement of Diffusion Coefficients by DC and EHD Electrochemical Methods. J. Electrochem. Soc. 135, 2279-2284, doi:10.1149/1.2096252 (1988).

156 Tribollet, B., Newman, J. \& Smyrl, W. H. Determination of the Diffusion Coefficient from Impedance Data in the Low Frequency Range. J. Electrochem. Soc. 135, 134-138, doi:10.1149/1.2095539 (1988). 
157 Antano-Lopez, R., Keddam, M. \& Takenouti, H. A new experimental approach to the timeconstants of electrochemical impedance: frequency response of the double layer capacitance. Electrochim. Acta 46, 3611-3617, doi:Doi 10.1016/S0013-4686(01)00640-5 (2001).

158 Cachet, H. et al. Capacitance probe of the electron displacement in a dye sensitized solar cell by an intermodulation technique: a quantitative model. Electrochim. Acta 49, 2541-2549 (2004).

159 Larios-Duran, E. R. et al. Dynamics of double-layer by AC Modulation of the Interfacial Capacitance and Associated Transfer Functions. Electrochim. Acta 55, 6292-6298, doi:10.1016/j.electacta.2009.10.036 (2010).

160 Antaño-López, R., Keddam, M., Turmine, M. \& Vivier, V. The Impedance Response of a Passive Film Revisited by a Double Modulation Technique. ChemElectroChem 6, 202-210, doi:10.1002/celc.201800737 (2019).

161 Zou, F., Thierry, D. \& Isaacs, H. S. A high-resolution probe for localized electrochemical impedance spectroscopy measurements. J. Electrochem. Soc. 144, 1957-1965, doi:Doi 10.1149/1.1837729 (1997).

This study reports the design of dual microelectrodes for performing local EIS for enhancing the spatial resolution of the technique.

162 Ferrari, J. V. et al. Influence of normal and radial contributions of local current density on local electrochemical impedance spectroscopy. Electrochim. Acta 60, 244-252, doi:10.1016/j.electacta.2011.11.053 (2012).

163 de Abreu, C. P. et al. Multiscale Electrochemical Study of Welded Al Alloys Joined by Friction Stir Welding. J. Electrochem. Soc. 164, C735-C746, doi:10.1149/2.0391713jes (2017).

164 Shkirskiy, V., Volovitch, P. \& Vivier, V. Development of quantitative Local Electrochemical Impedance Mapping: an efficient tool for the evaluation of delamination kinetics. Electrochim. Acta 235, 442-452, doi:10.1016/j.electacta.2017.03.076 (2017).

165 Gharbi, O., Ngo, K., Turmine, M. \& Vivier, V. Local electrochemical impedance spectroscopy: A window into heterogeneous interfaces. Current Opinion in Electrochemistry 20, 1-7, doi:10.1016/j.coelec.2020.01.012 (2020).

166 Creason, S. C. \& Smith, D. E. Fourier transform Faradaic admittance measurements: I. Demonstration of the applicability of random and pseudo-random noise as applied potential signals. J. Electroanal. Chem. 36, A1-A7 (1972).

167 Dokko, K. et al. Kinetic characterization of single particles of LiCoO2 by AC impedance and potential step methods. J. Electrochem. Soc. 148, A422-A426, doi:10.1149/1.1359197 (2001).

168 Stoynov, Z. B. \& Savova-Stoynov, B. S. Impedance study of non-stationary systems: fourdimensional analysis. J. Electroanal. Chem. 183, 133-144, doi:https://doi.org/10.1016/03681874(85)85486-1 (1985).

169 Itagaki, M. et al. In situ electrochemical impedance spectroscopy to investigate negative electrode of lithium-ion rechargeable batteries. J. Power Sources 135, 255-261, doi:10.1016/j.jpowsour.2004.04.004 (2004).

170 Huang, J., Li, Z. \& Zhang, J. B. Dynamic electrochemical impedance spectroscopy reconstructed from continuous impedance measurement of single frequency during charging/discharging. J. Power Sources 273, 1098-1102, doi:10.1016/j.jpowsour.2014.07.067 (2015).

171 Wiezell, K., Holmstrom, N. \& Lindbergh, G. Studying Low-Humidity Effects in PEFCs Using EIS II. Modeling. J. Electrochem. Soc. 159, F379-F392, doi:10.1149/2.006208jes (2012).

172 Setzler, B. P. \& Fuller, T. F. A Physics-Based Impedance Model of Proton Exchange Membrane Fuel Cells Exhibiting Low-Frequency Inductive Loops. J. Electrochem. Soc. 162, F519-F530, doi:10.1149/2.0361506jes (2015). 
173 Kulikovsky, A. A. Analysis of Damjanovic kinetics of the oxygen reduction reaction: Stability, polarization curve and impedance spectra. J. Electroanal. Chem. 738, 130-137, doi:10.1016/j.jelechem.2014.11.014 (2015).

174 Schneider, I. A., Kramer, D., Wokaun, A. \& Scherer, G. G. Oscillations in gas channels - II. Unraveling the characteristics of the low frequency loop in air-fed PEFC impedance spectra. J. Electrochem. Soc. 154, B770-B782, doi:10.1149/1.2742291 (2007).

175 Kuhn, H., Andreaus, B., Wokaun, A. \& Scherer, G. G. Electrochemical impedance spectroscopy applied to polymer electrolyte fuel cells with a pseudo reference electrode arrangement. Electrochim. Acta 51, 1622-1628, doi:10.1016/j.electacta.2005.02.108 (2006).

176 Raccichini, R., Amores, M. \& Hinds, G. Critical Review of the Use of Reference Electrodes in Li-Ion Batteries: A Diagnostic Perspective. Batteries-Basel 5, 24, doi:10.3390/batteries5010012 (2019).

177 Hoshi, Y. et al. Optimization of reference electrode position in a three-electrode cell for impedance measurements in lithium-ion rechargeable battery by finite element method. $J$. Power Sources 288, 168-175, doi:10.1016/j.jpowsour.2015.04.065 (2015).

178 Solchenbach, S., Pritzl, D., Kong, E. J. Y., Landesfeind, J. \& Gasteiger, H. A. A gold micro-reference electrode for impedance and potential measurements in lithium ion batteries. Journal of The Electrochemical Society 163, A2265 (2016).

179 Chu, Z. Y. et al. Testing Lithium-Ion Battery with the Internal Reference Electrode: An Insight into the Blocking Effect. Journal of the Electrochemical Society 165, A3240-A3248, doi:10.1149/2.0141814jes (2018).

180 Orazem, M. E. Electrochemical impedance spectroscopy: the journey to physical understanding. Journal of Solid State Electrochemistry 24, 2151-2153, doi:10.1007/s10008-020-04725-9 (2020).

181 Agarwal, P., Orazem, M. E. \& Garci-Rubio, L. H. Measurement models for electrochemical impedance spectroscopy. I. Demonstration of applicability. J. Electrochem. Soc. 139, 1917-1927 (1992).

182 Liao, H. et al. Physical Properties Obtained from Measurement Model Analysis of Impedance Measurements. Electrochimica Acta 354, 136747 (2020). 


\section{REVIEWER ACCREDITATION INFORMATION}

Nature Reviews Methods Primers thanks I. Shitanda, A. Lasia and S. Ciampi for their contribution to the peer review of this work.

\section{TABLE OF CONTENTS BLURB}

This Primer on electrochemical impedance spectroscopy (EIS) provides a guide to experimental design to measure impedance and how these data are analyzed. The range of applications that require EIS from measuring battery performance to electrochemical biosensors are highlighted. Limitations of the method along with emerging trends in experimental optimizations and data interpretation are also described. 
Fig. 1

a Electrochemical system Potentiostat

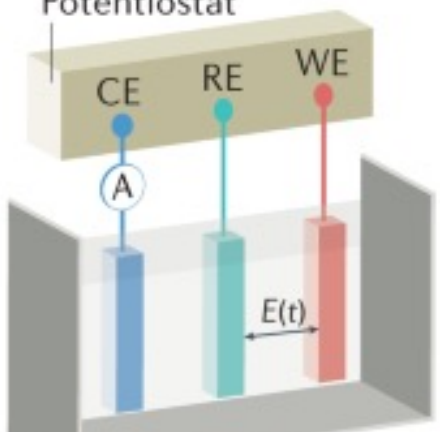

d Graphical representation

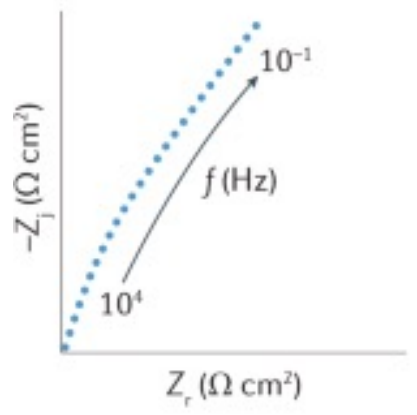

b Perturbation signal
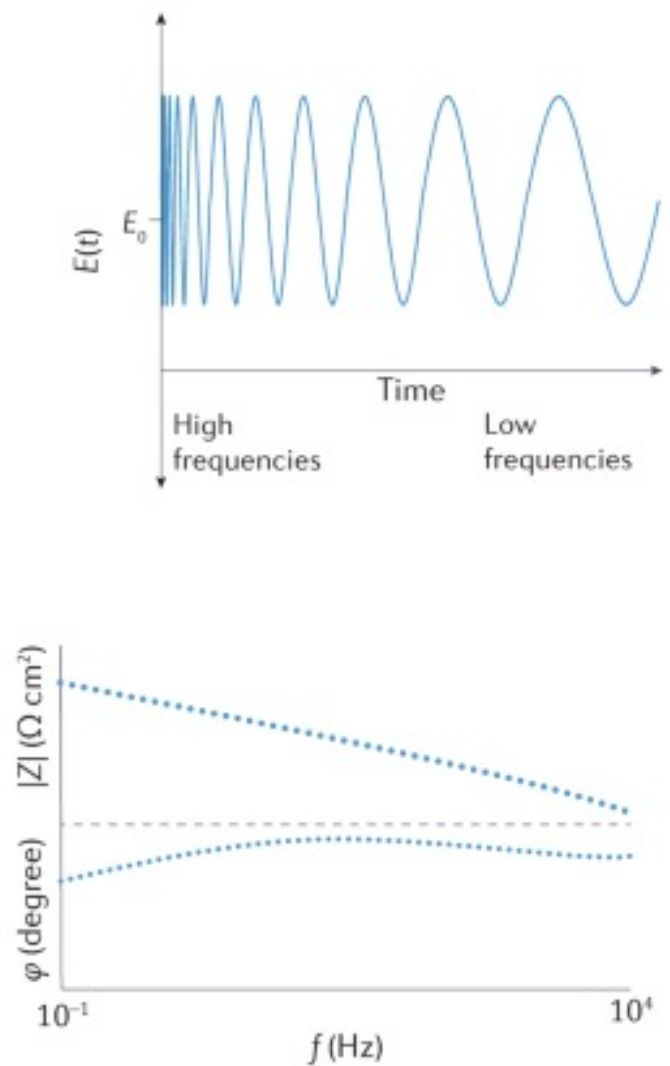

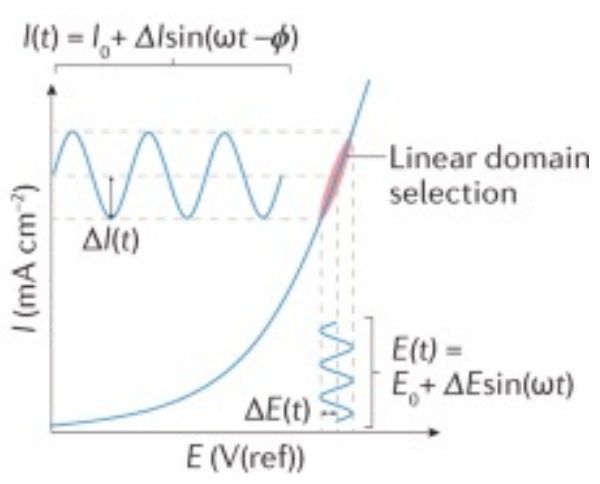

e Equivalent circuit and model

\section{c Electrochemical response}

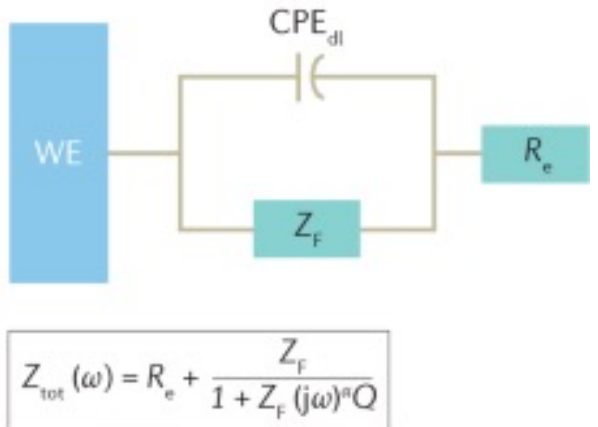


Fig. 2

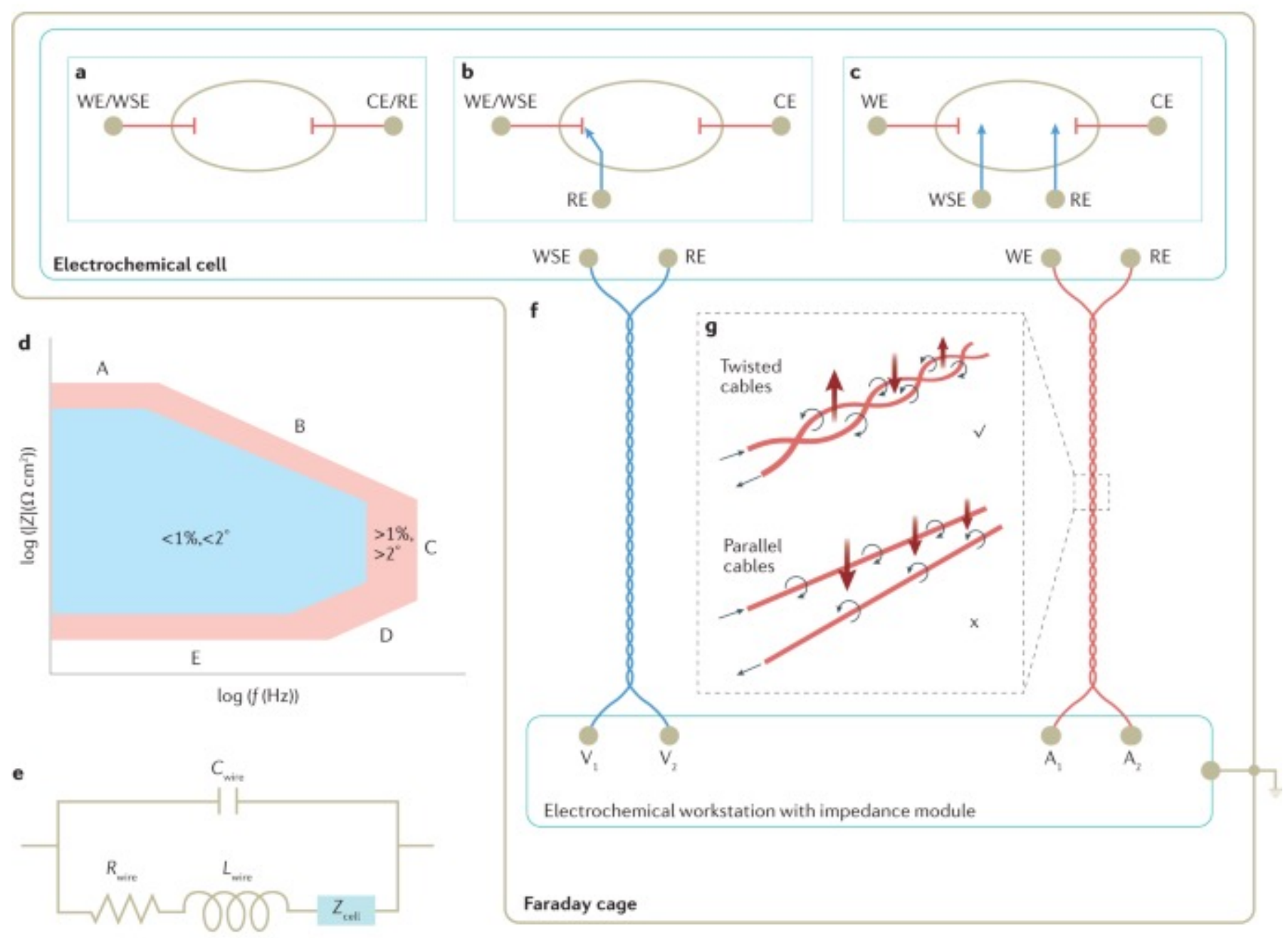


Fig. 3
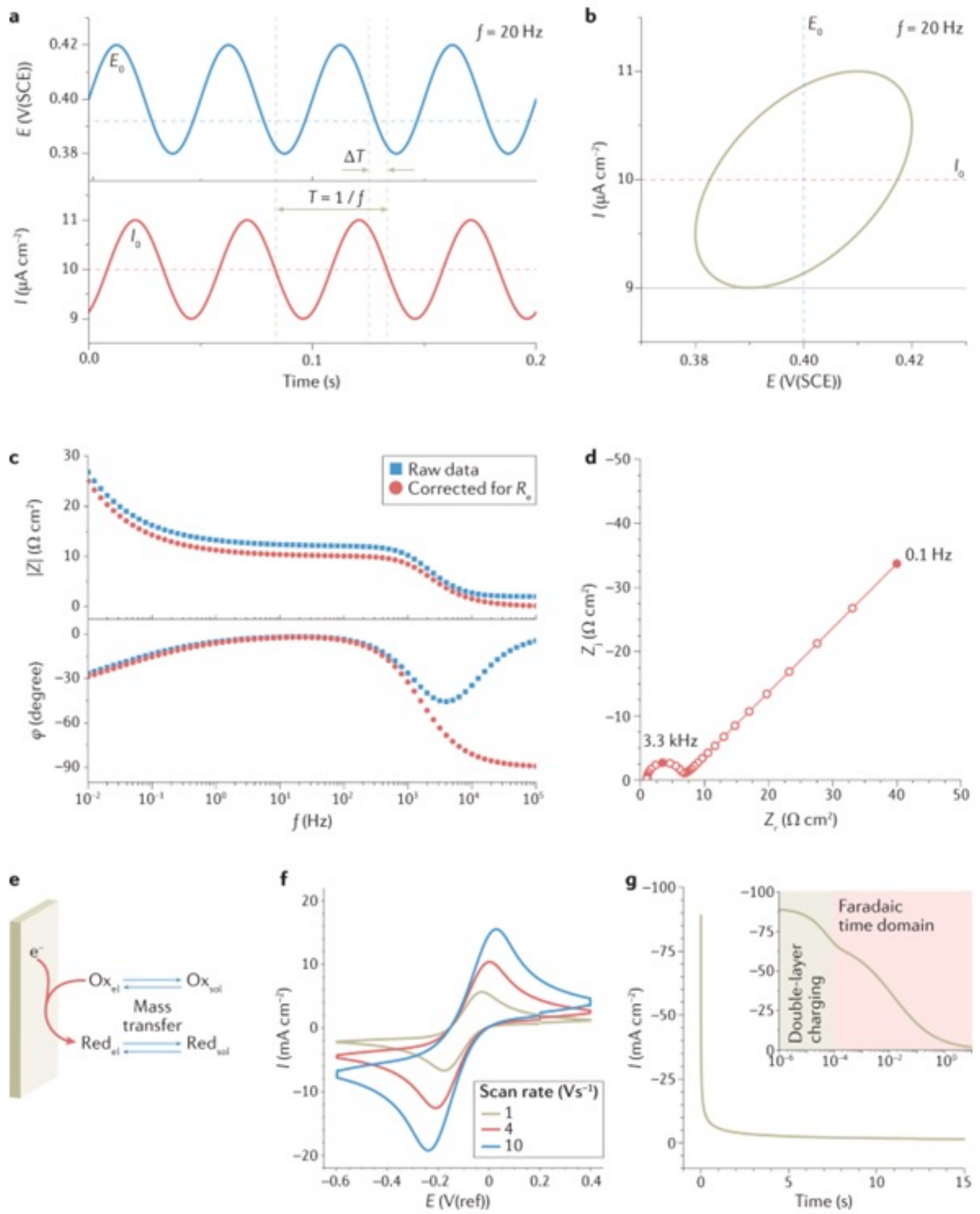
Fig. 4

a

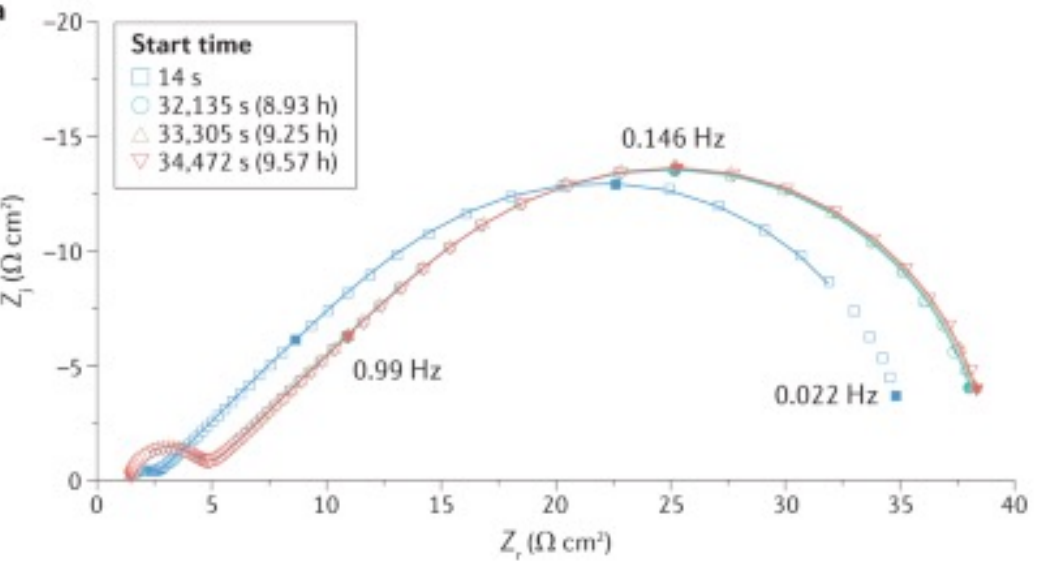

b

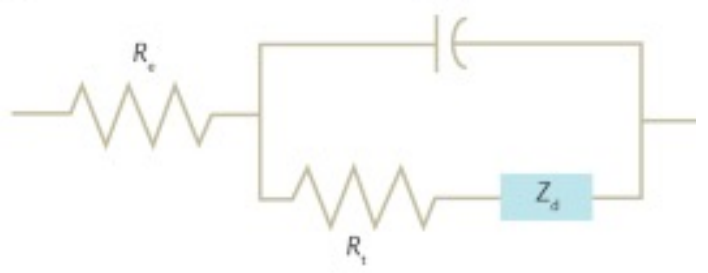


Fig. 5 :

a Typical EIS of iron corrosion in sulfuric acid solution

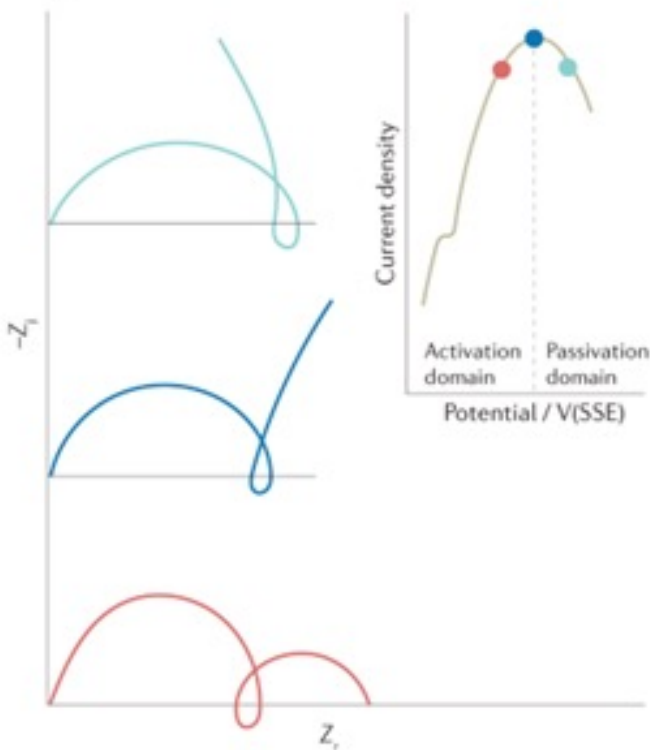

b Typical EIS of solid oxide fuel cells

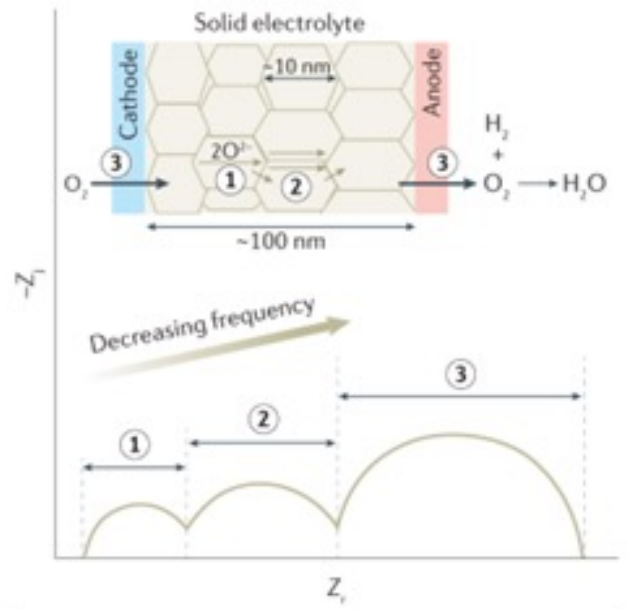

(1) Ion conduction within grains

(2) Ion conduction across or along grain boundaries

(3) Charge transfer at the electrode-electrolyte interface

\section{d Typical EIS of polymer electrolyte fuel cells}

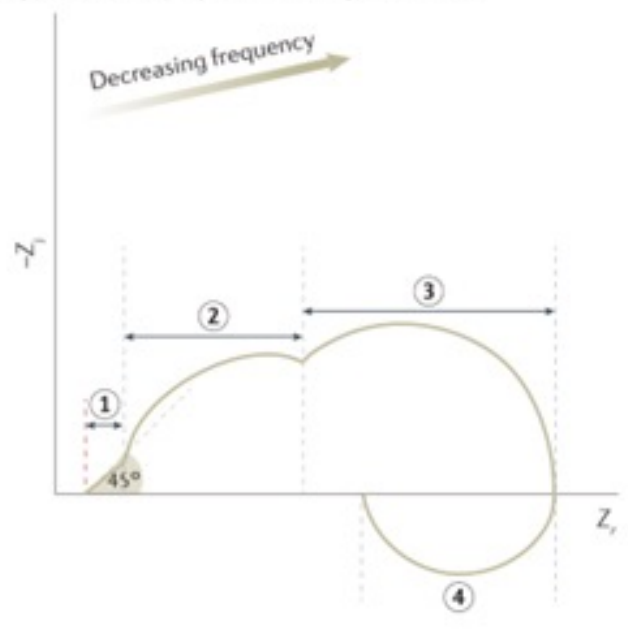

(1) Proton conduction in electrolyte membrane

(2) Charge transfer at the electrode-electrolyte interface

(3) Gas diffusion through gas diffusion layer

(4) Water transport across membrane or platinum oxide formation or relaxation of adsorbed intermediates for ORR 
Fig. 6
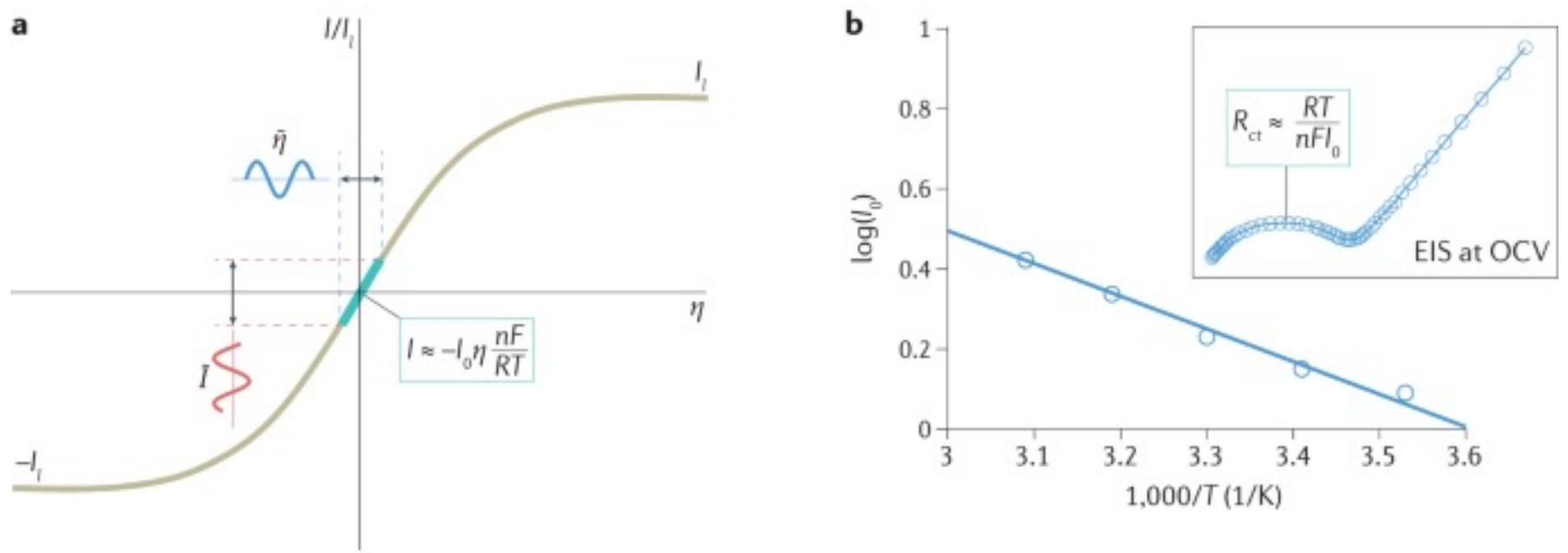
Fig. 7
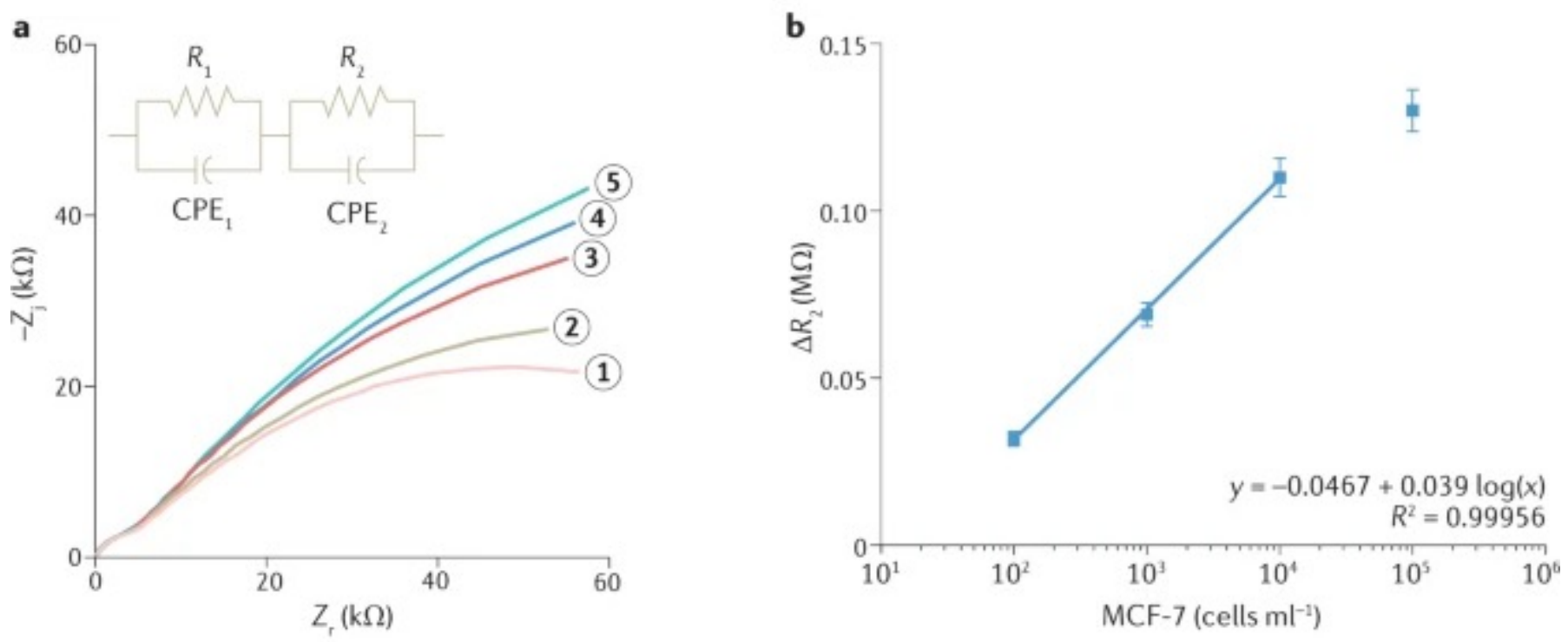
Fig. 8
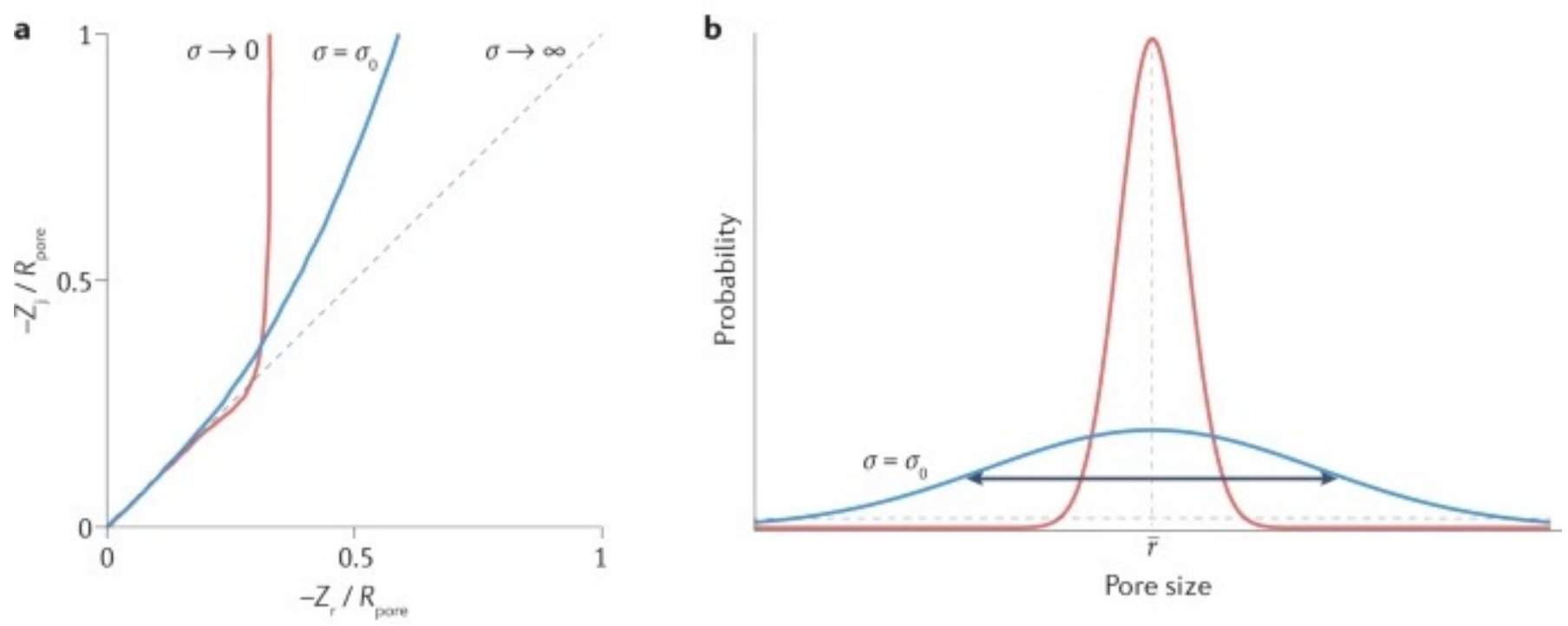
Fig. 9

a

$$
C_{1}=\frac{\tau_{1}}{R_{1}} \quad C_{2}=\frac{\tau_{2}}{R_{2}} \quad C_{k}=\frac{\tau_{k}}{R_{k}} \quad C_{K}=\frac{\tau_{K}}{R_{K}}
$$

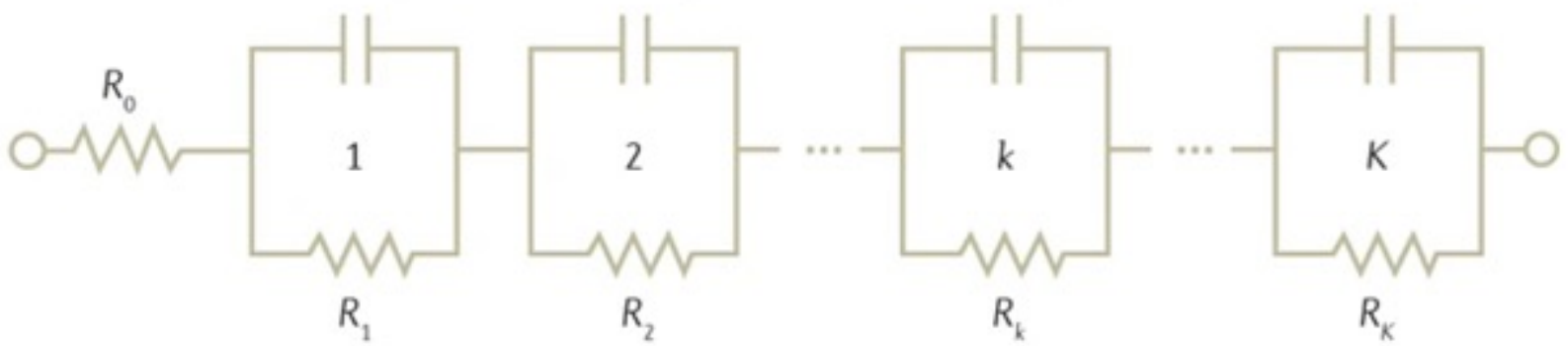

b

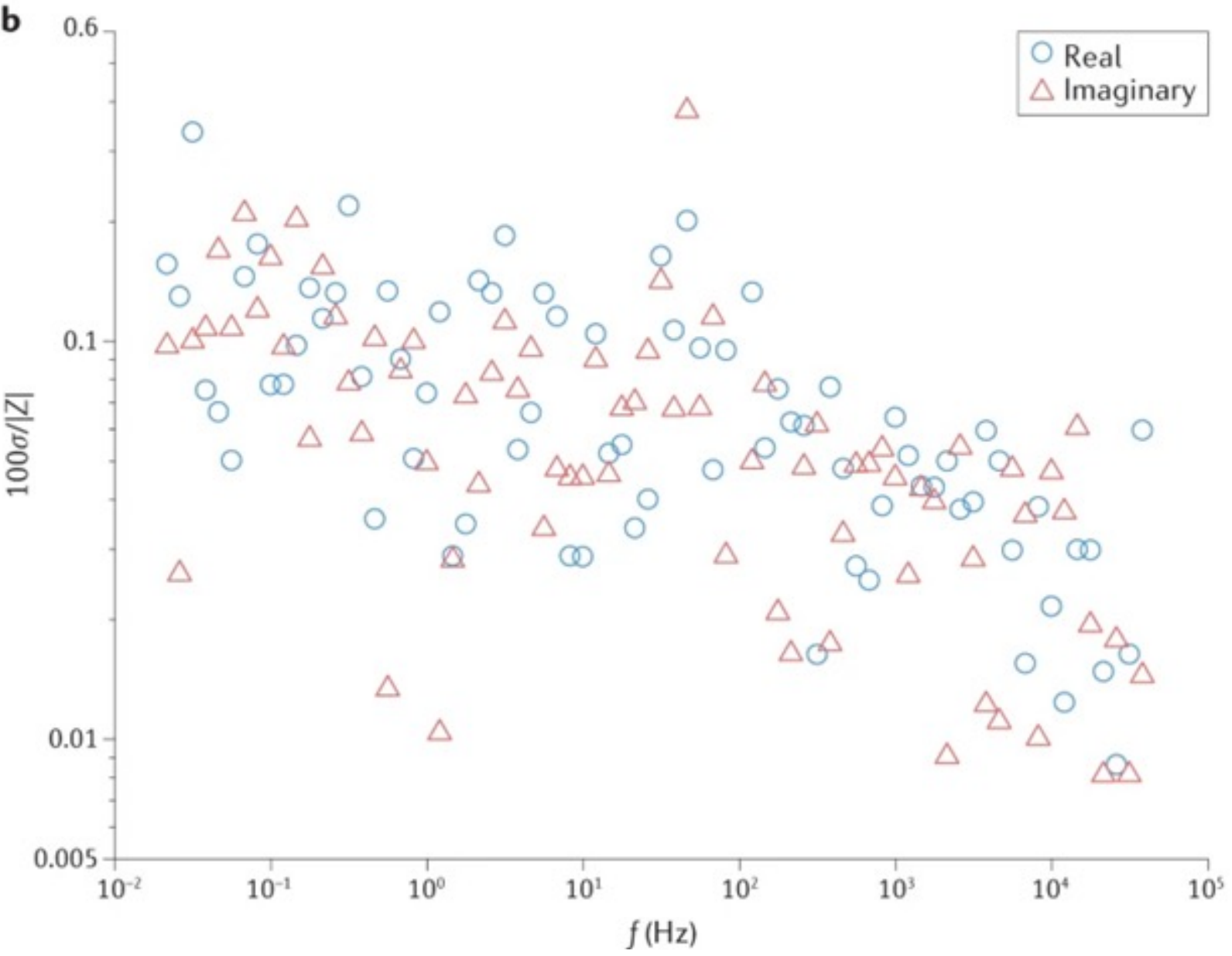

